\title{
Defining best practices for tissue procurement in immuno-oncology clinical trials: consensus statement from the Society for Immunotherapy of Cancer Surgery Committee
}

\begin{abstract}
Brian Gastman, ${ }^{1}$ Piyush K Agarwal, ${ }^{2}$ Adam Berger, ${ }^{3}$ Genevieve Boland (D) , ${ }^{4}$ Stephen Broderick, ${ }^{5,6}$ Lisa H Butterfield (1) , 7,8 David Byrd, ${ }^{9}$ Peter E Fecci, ${ }^{10}$ Robert L Ferris, ${ }^{11}$ Yuman Fong, ${ }^{12}$ Stephanie L Goff (D) , ${ }^{13}$ Matthew M Grabowski, ${ }^{14}$ Fumito Ito, ${ }^{15}$ Michael Lim, ${ }^{16}$ Michael T Lotze, ${ }^{17}$ Haider Mahdi, ${ }^{18}$ Mokenge Malafa, ${ }^{19}$ Carol D Morris, ${ }^{20}$ Pranav Murthy, ${ }^{21}$ Rogerio I Neves (D) ,22 Adekunle Odunsi, ${ }^{23}$ Sara I Pai, ${ }^{4}$ Sangeetha Prabhakaran, ${ }^{24}$ Steven A Rosenberg, ${ }^{25}$ Ragheed Saoud, ${ }^{26}$ Jyothi Sethuraman, ${ }^{27}$ Joseph Skitzki, ${ }^{28}$ Craig L Slingluff (1) , ${ }^{29}$ Vernon K Sondak, ${ }^{30}$ John B Sunwoo, ${ }^{31}$ Simon Turcotte, ${ }^{32}$ Cecilia CS Yeung, ${ }^{33}$ Howard L Kaufman ${ }^{4,34}$
\end{abstract}

To cite: Gastman B, Agarwal PK, Berger A, et al. Defining best practices for tissue procurement in immuno-oncology clinical trials: consensus statement from the Society for Immunotherapy of Cancer Surgery Committee. Journal for ImmunoTherapy of Cancer 2020;8:e001583. doi:10.1136/jitc-2020-001583

- Additional material is published online only. To view, please visit the journal online (http://dx.doi.org/10.1136/jitc2020-001583).

Accepted 12 0ctober 2020
Check for updates

(C) Author(s) (or their employer(s)) 2020. Re-use permitted under CC BY-NC. No commercial re-use. See rights and permissions. Published by BMJ.

For numbered affiliations see end of article.

Correspondence to Dr Howard L Kaufman; HLKaufman@mgh.harvard.edu

\section{ABSTRACT}

Immunotherapy is now a cornerstone for cancer treatment, and much attention has been placed on the identification of prognostic and predictive biomarkers. The success of biomarker development is dependent on accurate and timely collection of biospecimens and high-quality processing, storage and shipping. Tumors are also increasingly used as source material for the generation of therapeutic T cells. There have been few guidelines or consensus statements on how to optimally collect and manage biospecimens and source material being used for immunotherapy and related research. The Society for Immunotherapy of Cancer Surgery Committee has brought together surgical experts from multiple subspecialty disciplines to identify best practices and to provide consensus on how best to access and manage specific tissues for immuno-oncology treatments and clinical investigation. In addition, the committee recommends early integration of surgeons and other interventional physicians with expertise in biospecimen collection, especially in clinical trials, to optimize the quality of tissue and the validity of correlative clinical studies in cancer immunotherapy.

\section{INTRODUCTION}

Immunotherapy has dramatically changed the landscape for the treatment of patients with cancer, particularly over the past decade. ${ }^{1}$ Progress in tumor immunotherapy has led to enthusiasm for new and combination agents, a process that is highly dependent on biomarker analyses. Such biomarker studies identified programmed cell death ligand 1 (PD-L1) expression, tumor mutational burden, and presence of tumor infiltrating lymphocytes as important predictive factors in response to $\mathrm{PD}-1 / \mathrm{PD}-\mathrm{L} 1$ blockade in patients with non-small cell lung cancer (NSCLC) and other malignancies. ${ }^{2}$ Biomarker discovery and validation in tumor immunology require efficient collection of tumors to interrogate clinical response and biological mechanisms, as well as target tissues involved in immune-related adverse events, which could include any site in the body. Several thorough reviews reported on priorities and processes for biomarker assay development, ${ }^{3}{ }^{4}$ but few have addressed the technical aspects of biospecimen collection to define best practices for clinical studies of cancer immunotherapy. Tumors are also increasingly used as source material for the generation of tumorinfiltrating $\mathrm{T}$ lymphocytes in immunotherapy, but there currently are no standard guidelines on how to perform these procedures.

The Surgery Committee of the Society for Immunotherapy of Cancer (SITC) is a multidisciplinary group of surgeons who are interested in promoting tumor immunology and immunotherapy. The Committee asked surgical experts in specific areas of expertise to provide guidance and suggestions for best practices of collecting tumor/tissues from patients with cancer. This report provides a summary of consensus thinking on how to optimize immunotherapy biospecimen collection, with specific emphasis on tissue type and location. Our task force focused on 
methods for procuring high-quality and highly representative specimens that can yield new discoveries to impact the immunotherapy field, as well as establishing practices that can allow for more consistent clinical protocol development across studies and treatment sites.

\section{Basic science of biobanking}

Since humans are inherently diverse, a high level of standardization is needed to reduce technical noise and support reproducible studies of patient antitumor immunity. There are also technical requirements for different assay platforms and often a need to obtain viable cells for functional immune analyses or therapeutic drug preparation. Tumor tissue can be the most informative, yet the most diverse, due to intrapatient and interpatient tumor heterogeneity. The anatomical location of tissue, time from isolation to processing, processing sterility, tumor processing methods, storage conditions and temperature before processing are all critical variables that can impact the quality of biospecimens. Despite the importance of tumor tissue samples, there is no standard practice for obtaining them or for confirming their representation of the entire tumor. In addition, the ability to assess lymphoid infiltrates by 'radiomics' requires pathological assessment of surgical specimens in order to generate a 'ground truth' relationship to inferred changes in the tumor. ${ }^{5-10}$

\section{Importance of tissue sampling in immunotherapy clinical trials}

The recognition of tumor-specific mutations (neoantigens) is central to the success of immunotherapy. ${ }^{11-13}$ In addition, while tissue procurement is an obvious necessity in generating autologous tumor-infiltrating lymphocyte (TIL) treatments, enriched lymphocyte cultures may also serve as a research tool to understand the unique immunogenicity of each patient's tumor, and autologous tumor tissue can be characterized by DNA and RNA sequencing. ${ }^{13}$ In observations across different cancers, only $1 \%-2 \%$ of all somatic non-synonymous mutations are processed, presented, and recognized in the context of major histocompatibility complexes by autologous $\mathrm{T}$ cells. ${ }^{14}$ The recognition encoded in those rare $\mathrm{T}$ cells could be used to generate genetically engineered individual T-cell products or personalized tumor vaccines, and in the case of shared driver mutations, a human leukocyte antigen-restricted, off-the-shelf reagent for multiple patients. ${ }^{15}$ While tumor-specific $\mathrm{T}$ cells exist in the peripheral blood, they are found at significantly lower frequency (on average two log difference) compared with TIL. Efficient development of cell-based treatments, with important proof-of-principle clinical regressions, continues to require tumor procurement. ${ }^{16-19}$ For example, in the Surgery Branch of the National Cancer Institute, each tumor is processed into fragments for TIL generation, as well as (1) formal pathological evaluation, (2) snap-frozen samples for DNA and RNA extraction, (3) optimal cutting temperature (OCT) compound blocks for further immunohistochemical evaluation, (4) single-cell suspension for downstream applications, and (5) xenograft implantation when possible. A collection of peripheral blood lymphocytes, usually via apheresis, enhances the quality of immunologic assays.

Lymphocytes are not only involved in tumor destruction but also associated with what are now called immunerelated adverse events: lymphocytes are observed in the superficial and deep dermis of patients with severe dermatitis, the lamina propria of the colon in patients with severe colitis, and the hepatic portal triads of patients with severe hepatitis. ${ }^{20-22}$ Thus, optimizing tissue collection is expected to have a major impact on understanding how the immune system eradicates cancer, induces toxicity and can boost clinical benefit. We will focus first on how to standardize tumor collection for genomic and functional immune analyses, discuss how to best resect established tumors for extraction of $\mathrm{T}$ cells and finally provide best practices for tissue collection from specific anatomical locations.

\section{The changing landscape of tissue requirements for advanced transcriptional and proteomic analyses}

With the advent of new technologies for single-cell resolution omics and imaging, tissue procurement protocols need to allow for maximal information retrieval. There are two distinct categories of analysis that can be done: (1) retrospective (stored materials) and (2) prospective (fresh samples). Challenges with prospective collection relate to allocation of time and resources in an unknown cohort of patients (ie, unclear if paired pretreatment and post-treatment samples will be available, unknown therapy response), but better sample quality can be observed. Retrospective analysis allows better cohorting of patients and samples; however, it can limit analytical options due to current technical challenges with archival tissue. Several studies have indicated that archival formalin-fixed paraffin-embedded (FFPE) blocks can be used for molecular testing using PCR and next-generation sequencing (NGS) techniques despite nucleic acid degradation over time. ${ }^{23-25}$ Indeed, there are now recommendations for improving RNA extraction from FFPE tissues that ensure quality control by optimizing sequence library generation and applying appropriate software and technical parameters to identify RNAseq data artifacts, determine contamination, evaluate uniformity of gene coverage and assess gene expression reproducibility among biospecimen replicates. ${ }^{26}$ Applying modern quality controls for NGS has also been shown to improve the analysis of immunerelated gene expression in FFPE tumor biospecimens. ${ }^{27}$ These studies support the use of FFPE for immunological studies, and using current quality control measures helps support high accuracy and reproducibility of data derived from heterogeneous RNA samples.

Whenever feasible, fresh tissue may be preferred for both genomic and immune studies. Fresh tissue can be dissociated and readily used for single-cell RNA sequencing (scRNAseq) and single nucleus assay for 
transposase-accessible chromatin using sequencing for epigenetic analysis. ${ }^{28}$ Archived tissue that has been snap frozen can also be used for single-nucleus RNA sequencing. ${ }^{29} 30$ However, application of these approaches to specific tumor types can be a challenge, and certain cell types may be more sensitive to preanalytical processing, currently limiting broad-based adoption. There have been vast improvements in single-cell resolution imaging, including multiplexed imaging ${ }^{31} 32$ and combination multiplex imaging with RNA in situ hybridization (ISH). ${ }^{33} 34$ These can be done from FFPE tissues. In summary, best practice to allow for retrospective assessment of the transcriptome and epigenome includes saving a portion of tumor that is snap frozen, as well as preservation with OCT compound and/or FFPE in parallel.

The ability to provide fresh tissue-derived cells for ex vivo cell lines, injection into patient-derived xenograft (PDX) murine models, or use in organoid cultures requires collection of enough cells and maintenance of as much of the relevant in vivo function and phenotypical features of the immune cells as possible. ${ }^{35}$ While specific criteria for cell numbers and viability depend on each assay, collection of representative tumor areas and storage in appropriate media and/or preservative solutions is mandatory.

\section{Patient aspects associated with biospecimen sampling}

Biospecimens may be collected at one or multiple time points, depending on the goals of the tissue analyses, as summarized in table 1. Sequential biopsies, including pretreatment, on-treatment and post-treatment, can provide crucial insights into therapeutic effects on immune cell dynamics. ${ }^{36-38}$ Several challenges need to be considered when planning biospecimen collection.

\section{Tissue preservation}

The integrity of tissue and blood are altered over time; thus, collection and preservation should be performed rapidly and ideally at the bedside. Guidelines vary, but processing within $15 \mathrm{~min}$ is recommended whenever possible. Maintaining consistent processes and educated staff are crucial. Biospecimens allocated for genomic analysis should be subject to immediate storage in nucleic acid stabilizing reagents (RNAlater or Allprotect) to minimize degradation by pervasive DNases and RNases.

\section{Quality assurance}

Even if tumor biopsies are performed rapidly, the resulting samples can still be inadequate if most or all of the tumor sample is necrotic or if part of the sample is scar tissue, for example. Thus, all biopsies should be confirmed to contain sufficient tumor tissue based on evaluation of H\&E-stained slides. Similarly, analyses should include appropriate positive and negative controls and measures of reproducibility in the assay data.

\section{Shipping tissue}

When tissues are collected in multicenter trials, risks of sample degradation are increased by changes in ambient temperature during shipping, especially when shipping viable cells. ${ }^{39}$ When blood is collected, processing and preservation at each site has advantages but requires harmonization of methods among all sites. Alternatively, blood can be shipped centrally, but should be sent quickly and at room temperature. ${ }^{39}$ Shipping fresh solid tumor specimens for isolation of viable cells at a central site can subject the tumor tissues to extended warm ischemia time, which should be avoided. Current methods apply shipping in special media, including antioxidants at either room temperature or on wet ice to limit temperature swings with a 'tell-tale' to record temperature.

\section{Ethical considerations}

When biopsies are considered optional, they are rarely performed. Thus, the study goals are best served by biospecimen collection being required. However, the study design should include statistical justification for the sample size and anticipated endpoints. If tissue-based endpoints are primary or secondary, the analyses should be done with adequate controls and validation. In addition, risks must

Table 1 Examples of biospecimen source, timing and evaluable endpoints

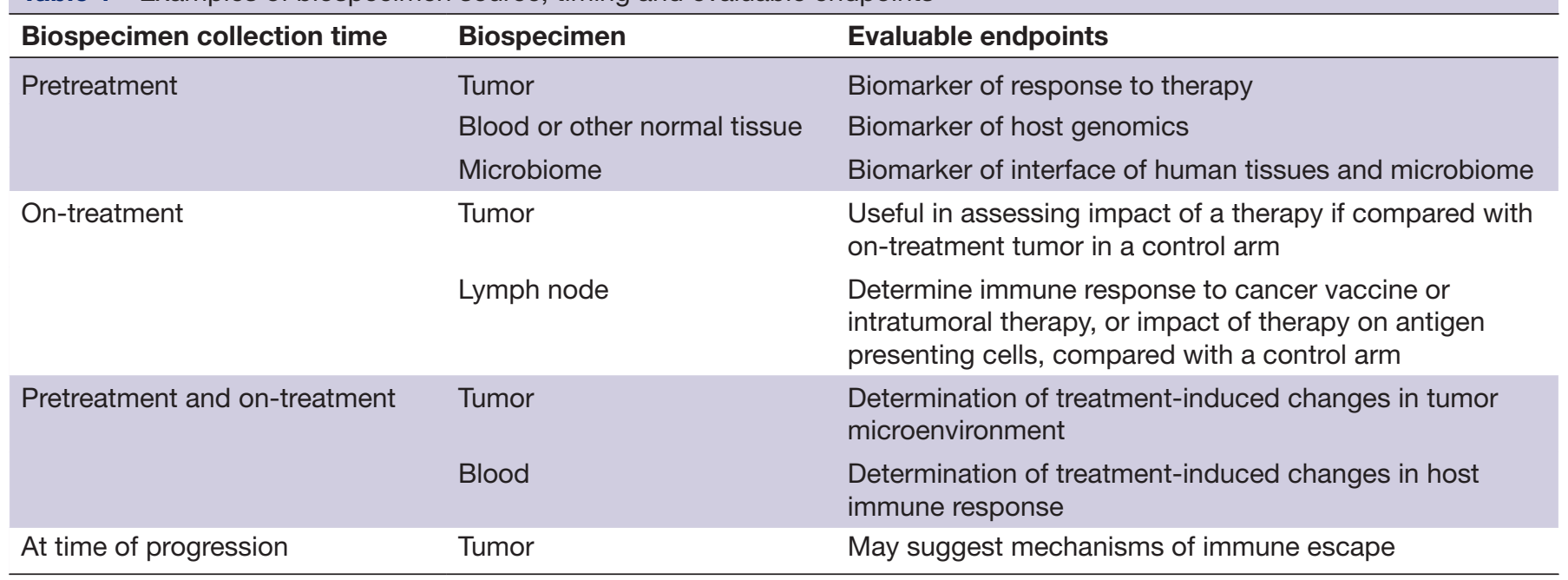


be weighed against potential benefit, and consent should comprehensively address all risks: these are responsibilities of the institutional review board and also the investigator. Patients with cancer may be willing to undergo extensive biopsies if participation provides hope for clinical benefit, but biospecimen collection should also consider broader ethical considerations. ${ }^{4041}$ In neoadjuvant trials, it is feasible to do a pretreatment core needle biopsy, followed by definitive resection after a defined interval. In those cases, there may be patient benefit to resection, but there is often little or no direct benefit of the extra pretreatment biopsy other than confirming the tumor pathology. A full discussion of all ethical issues around tissue collection is beyond the scope of this manuscript, but can be found in several review articles. ${ }^{41}$

\section{Coordinating tissue procurement in large clinical trials and cooperative group studies}

Large clinical trials represent very powerful resources to procure tumor tissue and other biospecimens in clearly defined groups of patients with detailed associated demographic, treatment and outcome data. At the same time, their decentralized nature and the involvement of multiple clinical sites with varying degrees of specialization and sophistication in tissue procurement introduce major challenges to investigators in terms of quality control. Other challenges include obtaining appropriate consent to use procured specimens for both planned and unplanned analyses; securing funding to collect, store and ultimately analyze samples; defining authorship priorities; and designing trials so that tissue procurement requirements are reasonable, feasible and will not hamper patient recruitment. As immuno-oncology drugs enter the marketplace, cooperative groups are increasingly likely to become involved in large, multicenter evaluations that may study clinical scenarios different from those that resulted in the original approval of the drugs for clinical use. Thus, biospecimen collection in cooperative group studies offers unique opportunities for tissue collection and immunological investigation.

\section{Proper tissue procurement in neoadjuvant immunotherapy clinical trials}

Neoadjuvant studies represent a particularly unique situation where therapeutic intervention is followed by an operation to remove an established cancer. This provides an opportunity to obtain tissue from a potentially curative resection for immunological study. In this setting, ensuring enough tissue is available for diagnostic assessment prior to research investigation is of paramount importance. This is expected to become a more important part of immunotherapy development in the future, as recent studies have shown remarkable therapeutic responses to immune checkpoint blockade when given in the neoadjuvant setting. ${ }^{42}$ Close communication and coordination between the surgeon and pathologist are essential with pre-established processes for ensuring enough tissue is available for diagnostic evaluation, and tissue for biomarker analysis should be managed as appropriate for the planned immune assays.
Tumor samples should contain a high enough tumor burden to test for various biomarkers and meet sample criteria for both molecular testing by NGS and immunohistochemistry. This includes a minimum tumor nuclei percentage of $20 \%$ or higher, and minimal necrosis when possible, although samples with apoptosis may yield DNA suitable for NGS. ${ }^{43}$ Additional considerations include plans for a pretreatment biopsy to allow for comparisons after neoadjuvant treatment with the surgical specimen. This biopsy needs to be done prior to systemic treatment and should not substantially alter the tumor as to prevent evaluation of treatment or response. Simultaneous collection of peripheral blood specimens is also helpful in the analysis of neoadjuvant therapy, and ideally, this should be done at the time of pretreatment biopsy and at surgery. The timing of surgery is also an important variable to consider when implementing neoadjuvant studies, and surgical guidance on appropriate durations for delay of surgical intervention should be considered and may vary based on the underlying biology of different cancers and patient populations. In addition, surgeons familiar with the underlying cancer should be included in defining resectability in patients enrolled in neoadjuvant immunotherapy clinical trials.

\section{Harvesting metastases to generate tumor-infiltrating $T$ lymphocytes for adoptive cell transfer immunotherapy}

Given ongoing developments in TIL immunotherapy, surgeons with various expertise will be increasingly involved in the procurement of metastases for clinical-grade TIL manufacturing and research. Specific considerations apply when harvesting tissue for TIL immunotherapy:

\section{Patient selection}

Patients with rapidly progressing cancers are not good candidates, since TIL manufacturing can take up to 5 weeks. To successfully recover from surgery and subsequently undergo 1 week of lymphodepleting chemotherapy prior to TIL infusion, patients must be fit, without significant comorbidity, latent infection, immune disease or chronic intake of corticosteroids, and with good nutritional status. A washout period from previous systemic therapy may be necessary.

\section{Target lesion(s)}

Close collaboration with the immunotherapy team is needed so that surgeons resect specific metastases for TIL manufacturing while other measurable metastases are left untouched for determination of treatment efficacy. For TIL manufacturing, most protocols require at least one tumor of approximately $2 \mathrm{~cm}^{3}$. As noted previously, a radiomic method to select lesions for greater lymphoid infiltrate is a potential area for exploration.

\section{Surgical invasiveness}

The goal is to harvest sufficient tumor material for TIL manufacturing while favoring the least invasive technique. Improper wound healing, surgical site infections, leaks, and physical deconditioning can render patients ineligible for timely lymphodepletion and TIL infusion. 


\section{Tumor handling}

Sterility cannot be breached. Immediately after resection, the tumor should be placed into a specific, preidentified, sterile container on the surgical field. Transportation media with appropriate antibiotics and/or antifungal agents may be necessary, as well as a temperaturecontrolled transportation device for shipment to an external cell production facility.

\section{Histopathological assessment, tumor processing and biobanking} Tumors harvested for TIL manufacturing should be handled fresh in a cell culture cabinet that meets specific grades in a controlled environment. Most of the tumor will be used for TIL production, but some is necessary for FFPE processing and confirmation of histological diagnosis. Macroscopic data are typically obtained prior to processing, but surgical margins are irrelevant in the context of plurimetastatic patients and non-curative resections. Additional tissue may be cryopreserved for correlative research.

\section{TECHNICAL ISSUES AND SPECIFIC TISSUE CONSIDERATIONS Cutaneous tissues}

The appropriate handling of cutaneous tissues procured for research purposes can be facilitated by having a pathologist or dermatopathologist working together with the surgeon in the actual procurement of the tissue. This is particularly important when dealing with small tumor samples like primary melanoma and other skin cancers to prevent compromise of diagnostic specimens. Specimen collection containers should be prelabeled with barcode/ donor ID for high-volume collections to improve workflow and ensure accurate labeling and specimen tracking.

If not processed immediately, specimens should be placed in a clean or sterile container on wet ice $\left(2^{\circ} \mathrm{C}-8^{\circ} \mathrm{C}\right)$ for transport from surgery to pathology or to the repository. If samples are to be used for establishing cell lines or tumor-derived xenografts, it is ideal for the specimen to be transported immediately to the pathology laboratory. Most institutions will have a biorepository technician available to do this when notified ahead of time.

To avoid desiccation and compromise of subsequent analyses, cutaneous specimens should not be resected on a dry towel or other absorbent material. Unless previously specified, tissue provided to the repository may be placed directly in appropriately labeled clean containers of cold biopreservation media $\left(2^{\circ} \mathrm{C}-8^{\circ} \mathrm{C}\right)$ for transport to the repository for processing. If the tissue is to be frozen immediately, it is not necessary to place it in preservation media. Such media may cause ice crystals to form on the outside of the specimen when freezing.

Data should be maintained and tracked on the time that elapses between relevant time points (collection, processing, preservation, and storage). A date and time stamp can be used for maintaining these records efficiently. Information from the pathologist on the characteristics of the biopsy or surgical material (eg, percentage normal, percentage tumor, percentage necrosis, and/or percentage fibrosis) as determined by microscopic evaluation should be obtained on a per-specimen basis and recorded.

An important consideration for immunotherapy trials is the fact that tumors in the skin and dermis provide ready access to multiple and sequential biopsies. This can be the case for those on neoadjuvant treatment protocols as well as those on treatment trials for metastatic disease who still have their primary (or local recurrence) intact. In these cases, small ( 2 or $3 \mathrm{~mm}$ ) punch biopsies should be done to sample the tumor while still allowing for response assessment. Additionally, small punch biopsies can simultaneously sample normal adjacent skin.

\section{Lymph nodes (LNs) and nodal basin tissue}

Regional LNs are the primary site of immune responses to vaccines and intratumoral immune therapies; thus, procurement of $\mathrm{LN}$ tissue provides critical information on the immune response to regional cancer immunotherapy. Palpable tumor-involved nodes can be biopsied at the patient bedside with a spring-loaded core needle biopsy instrument. Successful sampling depends on obtaining sufficient tissue to be representative of the tumor specimen. The volume of tissue obtained with a core needle biopsy depends on the inner diameter of the core needle and the 'throw distance', which defines the length of the core obtained (see table 2). Our routine practice is to obtain at least four core biopsies on each biopsy date, using a $14 \mathrm{G}$ needle with a $2 \mathrm{~cm}$ throw distance. These can be obtained under local anesthesia through one small skin incision, with each sample placed immediately into preservation conditions. This is ideally done with staff at

Table 2 Tissue volume obtained with core needle biopsy based on inner diameter and throw distance

\begin{tabular}{lllcc} 
& & & \multicolumn{2}{c}{ Core biopsy volume $\left(\mathbf{m m}^{3}\right)$} \\
\cline { 4 - 5 } Needle size (G) & Inner diameter $(\mathbf{m m})$ & Cross-sectional area $\left(\mathbf{m m}^{\mathbf{2}}\right)$ & 2.8 & 5.6 \\
\hline 20 & 0.60 & 0.28 & 5.5 & 11.0 \\
18 & 0.84 & 0.55 & 11.1 & 22.2 \\
16 & 1.19 & 1.11 & 20.1 & 40.2 \\
14 & 1.60 & 2.01 & 36.6 & 73.2 \\
\hline 12 & 2.16 & 3.66 & $\mathbf{c m}$ throw \\
\hline
\end{tabular}


Table 3 Tissue preservation conditions and available analyses

\begin{tabular}{ll}
\hline $\begin{array}{l}\text { Tissue preservation } \\
\text { condition }\end{array}$ & $\begin{array}{l}\text { Tissue analyses available from } \\
\text { this tissue }\end{array}$ \\
\hline Liquid nitrogen & $\begin{array}{l}\text { Protein, RNA, DNA, histology, } \\
\text { IHC, mIF }\end{array}$ \\
\hline RNAlater & RNA \\
\hline $10 \%$ formalin & DNA, histology, IHC, mIF \\
\hline Tissue culture media (eg, & $\begin{array}{l}\text { Creation of single cell } \\
\text { RPMI 1640) } \\
\text { functional assays, single-cell } \\
\text { analyses }\end{array}$ \\
\hline
\end{tabular}

IHC, immunohistochemistry; mIF, multiplex immunofluorescence; RPMI, Roswell Park Memorial Institute.

the bedside in the procedure room, with liquid nitrogen, RNAlater, formalin and tissue culture media. Table 3 shows the preferred preservation conditions based on the type of biospecimen analyses being planned.

Biopsy of putatively normal LNs commonly requires localization using the techniques of sentinel LN biopsy, such as ${ }^{99 \mathrm{~m}} \mathrm{Tc}$ sulfur colloid localization. This can be done with minimal morbidity under local anesthesia in a clinic setting. ${ }^{44}$ LN biopsy can rarely cause lymphedema, but we find that if the injection is in the lateral-anterior proximal thigh, removing an inguinal $\mathrm{LN}$ should be associated with a very low risk of lymphedema. Axillary nodes can also be biopsied, but some are deep and more challenging to remove. The node can be mechanically disaggregated, providing approximately 100 million immune cells for functional immune analyses, to be assessed fresh or viably cryopreserved in aliquots for later analyses. ${ }^{44}$ Example text describing these methods is provided in the online supplemental appendix.

\section{Muscle and other soft tissues}

The sampling of either primary or metastatic tumors in soft tissues and muscle, in the context of immunotherapy, is dependent on several variables, including anatomical location, size of the target lesion, intent and extent of the resection and invasiveness to the patient. The prioritization of tissue is often necessary, whether it is a full excisional biopsy or several core needle biopsies. The average tissue collection from a single $18 \mathrm{G}$ core needle biopsy with a $2 \mathrm{~cm}$ throw distance is a little over $10 \mathrm{~mm}^{3}$ $(\sim 10 \mathrm{mg})$, but can be highly variable, depending on the consistency of the tissue and adequacy of biopsy. ${ }^{45}$ Thus, a larger core can be considered or more samples can be collected. When possible, larger core needle biopsies including 12, 14 and $16 \mathrm{G}$ yield a higher amount of tissue as previously noted (see table 2 ), although the weight and amount of actual tumor tissue obtained are related to the consistency and composition of the tumor and its stromal elements.

The sample size is crucial as it may directly influence the type of testing and the number of analyses performed.
Specifically, IHC performed for tumor-associated immune markers such as PD-L1 has been shown to be directly dependent on the amount of tissue analyzed ${ }^{46}$; therefore, the greater the tissue quantity obtained, the greater the potential accuracy. Typically, samples are immediately weighed, segmented, and frozen with a single slide for hematoxylin and eosin (H\&E) staining created to confirm the adequacy of the specimen including bona fide tumor tissue. The percent of neoplastic nuclei, necrosis, and overall cellularity are recorded for each specimen as it directly influences the yield of DNA or RNA that can be extracted. In general, samples with 30\%-40\% neoplastic nuclei and less than $20 \%$ necrosis are acceptable for most uses. Tissue should be collected fresh to allow for flow cytometry, RNAseq, and mass spectrometry as formalin fixation will preclude several types of analyses. Immediate snap freezing in liquid nitrogen can be performed at the site of tissue collection. The remaining tissue portions can then undergo formalin fixation and IHC or ISH can be used to generate a picture of immune cell subsets. The peripheral versus central area of the tumor can be defined by simple IHC and comparison to H\&E slides, which may reflect an evolving immune response if samples are taken across time. The actual time limit for tissue collection and extracting adequate RNA is variable with several factors, including devascularization of tissue in surgical specimens, processing time for standard pathology assessments, and time to quality-check the material. RNA may still be of good quality if the total time to freezing or processing is less than 2 hours. ${ }^{47}$

\section{Breast tissue}

Management recommendations for patients with breast cancer have centered on immunohistochemical expression of hormone receptors and human epidermal growth factor receptor 2 (ER/PR/HER2). mRNA-based gene expression assays render molecular signatures that provide additional guidance for treatment and relapse risk assessment. Tissue removed for clinical and research studies includes core needle biopsies, lumpectomy, and total mastectomy. Core needle biopsies should be placed immediately into $10 \%$ neutral buffered formalin.

$\mathrm{Up}$ to $60 \%-70 \%$ of laboratory-associated errors are due to preanalytical factors. ${ }^{48} \mathrm{~A}$ major problem in tissue procurement from resection specimens is the lack of quality standardization for preanalytical variables, ${ }^{48} 49$ most importantly, cold ischemia time and total time in formalin. Best practice guidelines for ER/PR/HER2 assays were recently updated. ${ }^{49}$ These guidelines recommend a cold ischemia time of $<60 \mathrm{~min}$ and total time in formalin of 6-72hours based on assessment of ER/PR status. Further studies are needed to define the impact of cold ischemia time on tissue collected from other anatomical sites. For breast tissue, cold ischemia time, fixative type, and time the sample was placed in neutral buffered formalin must be recorded. Further delays in tissue processing may be incurred when surgery centers are located far from academic/research centers. Compliance 

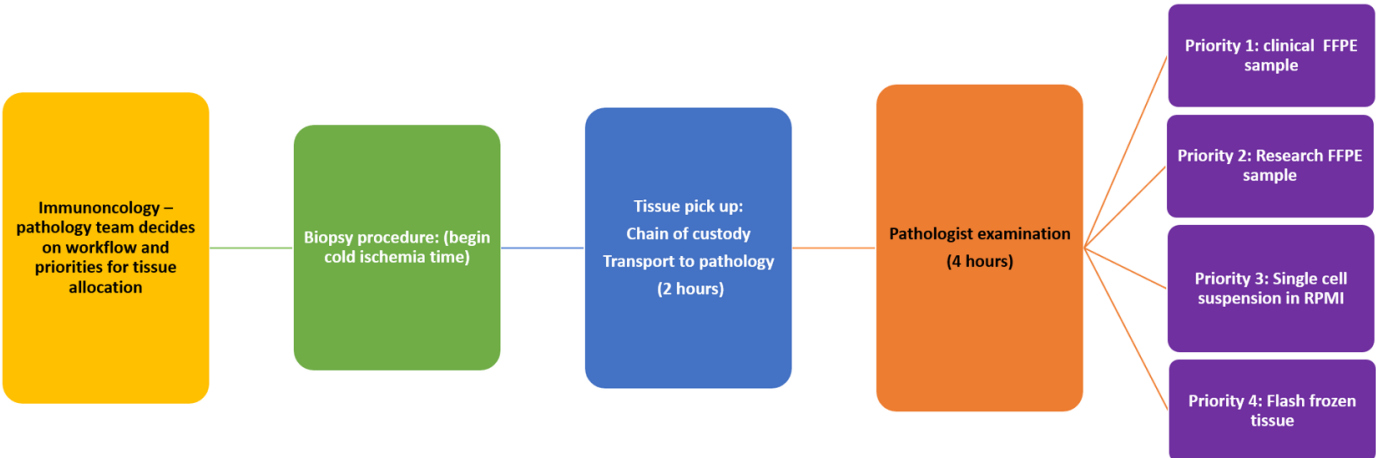

Figure 1 Biopsy tissue acquisition in immuno-oncology clinical trials is a team approach. A standard process from one academic center that employs a tight chain of custody and real-time pathologist triage of patient samples in order to maximize the utility of biopsied material. A teams-based approach to review protocols helps develop specimen acquisition laboratory workflows that keep priorities for tissue allocations clear to each member of the team involved (yellow). Cold ischemia time begins at tissue removal and involves team coordination: nursing, clinical and research coordinators provide specific instructions for collection to the surgeon and the pathology retrieval team (green). The research technologist picks up the specimen at the collection site, establishes a chain of custody and time stamp on the tissues, and transports to clinical trials pathology lab (blue), where the pathologist examines tissues for viable tumor, necrosis, crush and hemorrhage artifact, grosses in and splits the tissue (orange), and sorts according to priority list (purple). In our experience, formalin fixation (purple, priorities 1 and 2) still represents the highest priority preservation because of its wide usage and relative standardization. When possible, grossing the tissues into two blocks, one allocated for clinical diagnosis and one allocated for research, is best as preservation of the clinical specimens is a regulatory requirement. The next most useful sample is a single-cell preparation in RPMI (purple, priority 3), where single-cell RNA sequencing (eg, 10× genomics) and highly multiparametric mass cytometry (Cytometry by time of flight, CyTOF), particularly in conjunction with multiplex immunohistochemistry, can yield deep insights into mechanisms of response and non-response to immuno-oncology agents. Finally, as in purple, priority 4, any remaining tissue after formalin fixation and tumor disassociation is flash frozen, either in liquid nitrogen or cryopreserved in OCT compound. FFPE, formalinfixed paraffin-embedded; OCT, optimal cutting temperature; RPMI: Roswell Park Memorial Institute.

with these guidelines is not mandatory, leaving breast surgeons and pathologists to voluntarily collaborate to develop and implement standards of practice. In addition to rapid collection, a clear chain of custody, including time-stamped documentation of the preanalytical variables, should be required. Figure 1 describes a detailed time flowchart from tissue procurement through prioritization into samples for clinical and research labs.

\section{Head and neck tissues}

For head and neck squamous cell carcinomas (HNSCCs), the threshold in tumor size for tissue collection is typically $\geq 1 \mathrm{~cm}$ at the primary site and/or in the metastatic tumor-involved cervical LNs. These are general guidelines that help minimize potential compromise to clinical care and may vary, depending on the institution and the involvement of the pathologists at the time of collection. In HNSCCs, the presence of pathological extranodal extension in the metastatic cervical LN can influence the staging of HNSCCs, in particular, human papillomavirus (HPV) -negative HNSCCs, and subsequent treatment guidelines. Thus, involvement of a pathologist to procure the cancer tissue is highly encouraged, if not required.

For immunological-based assays, non-cancerous involved tissue may often be needed as a comparative 'control', and this can include either adjacent normal tissue or non-tumor involved LNs. As part of a quality assurance measure in assessing the adequacy of a neck dissection and for accurate staging purposes, the pathologist reports on both the number of involved nodes and the total number of excised LNs. Thus, coordination with a pathologist in the sampling of LNs is also necessary to provide optimal clinical care and to ensure accurate reporting of the number of LNs removed at the time of the neck dissection.

Since the oral cavity is a major gateway of entry into the body, many head and neck cancers have background bacterial and/or fungal infections that have implications when trying to establish short-term and/or long-term cancer cell cultures. Thus, antifungals and/or antibiotics often need to be placed in the transport and/or culture medium to facilitate the preferential growth of the tumor cells in vitro. Oral rinse and/or saliva samples may also be included in the collection of biological specimens for patients with head and neck cancer. However, oral rinse and/or saliva samples may be most useful for genomicbased work since there is controversy in the field on the utility of using these samples to study the oral microbiome based on background contamination of the oral cavity. Unique to HNSCCs is also the field's distinction between HPV-positive and HPV-negative HNSCCs. When collecting HNSCC tissue, it is recommended to record these two distinct categories whenever possible, because this will facilitate the analysis and/or subanalysis of the tissue samples in the future. Lastly, given the accessibility of head and neck cancers based on their location, there is an opportunity to obtain serial tumor biopsy samples during therapy, which can inform biomarker development, as well as provide insight into mechanisms of 
investigational therapies and associated changes induced within the tumor microenvironment (TME).

\section{Lung and other thoracic tissue}

Multiple prospective trials have demonstrated improved survival with administration of immunotherapeutic agents (PD-1/PD-L1 blockade) either alone or in combination with cytotoxic chemotherapy in advanced NSCLC, and more recently for small cell lung cancer. ${ }^{50-56}$ Treatment selection considerations in this population include tumor histology, PD-L1 levels and the presence of epidermal growth factor receptor, anaplastic lymphoma kinase, or ROS proto-oncogene 1 driver mutations. Thus, in advanced disease, pretreatment biopsy is critical for selection of first-line therapy. In most patients presenting with advanced disease, the primary tumor or metastatic sites are readily available for percutaneous core needle biopsy. Central tumors may also be amenable to bronchoscopic approaches, although with generally lesser quantities of tissue. Collection of bronchoalveolar lavage specimens at the time of bronchoscopy facilitates microbiome studies.

The efficacy of checkpoint inhibition in patients with metastatic NSCLC has prompted much interest in the application of immunotherapeutic agents in resectable disease. Recent phase I/II studies have demonstrated impressive pathological responses to neoadjuvant checkpoint inhibition ${ }^{57-61}$ and multiple phase III studies powered for survival endpoints are in various stages of accrual. Studies to date employ major pathological response and complete pathological response (CPR) as surrogate endpoints for efficacy. Thus, standardization of the processing and interpretation of pathological materials is paramount for comparison across histologies, neoadjuvant treatments and trials. The International Association for the Study of Lung Cancer has recently published recommendations for the pathological assessment of lung cancer resection specimens following neoadjuvant therapy. ${ }^{62}$

Central mediastinal LNs (ie, paratracheal and subcarinal) are most commonly biopsied via endobronchial ultrasound-guided needle aspiration. However, when more substantial tissue quantities are required, mediastinoscopy may be necessary. Anterior mediastinotomy (Chamberlain procedure) can provide tissue from anterior mediastinal or aortopulmonary window LNs not accessible by percutaneous techniques. Similar approaches can be used to obtain tissue from the thymus or other anterior mediastinal tumors. Processing of nodal specimens should be performed as delineated elsewhere in this review (see table 3 ).

\section{Colorectal tissue}

Immunotherapy is useful for patients with colorectal cancer (CRC) with microsatellite instability (high), and high mutational burden, ${ }^{63}$ but is typically more effective if checkpoint targets are present, along with increased CD8+ T-cell infiltration. ${ }^{65}$ In patients with deficient mismatch repair, as high as $90 \%$ CPR has been reported. ${ }^{66}$ Chalabi et al reported a $95 \%$ major response and a $60 \%$ complete response in early-stage, mismatch repair deficient (dMMR) colon cancers treated with ipilimumab+nivolumab. ${ }^{67}$ For patients with intact mismatch repair, 27\% showed response to therapy, with $\mathrm{CD} 8+$ / PD-1+ T-cell infiltration predicting response. ${ }^{67}$ These data support the role of tumor histology, MMR status, PD-1/ PD-L1 levels and CD8+ T-cell infiltration, along with the mutational status of BRAF and KRAS, as important biomarkers in CRC that may be useful in patient selection for immunotherapy.

Assessment of tumor immune infiltrates in CRC is complicated by the high level of immune cells in the gut, including gut-associated lymphoid tissue rich in lymphocytes that protect the epithelial barrier. ${ }^{68}$ The lamina propria contains antigen-presenting cells, innate lymphoid cells, CD4+ and CD8+ T cells, and B cells that affect immune responses throughout the body. Subverted organization of colonic crypts, chronic inflammation, and oxidative stress expose cancer stem cells in CRC to non-canonical signaling pathways, affecting their selfrenewal and adaptability to therapy. ${ }^{69-71}$ The microbiome also plays a critical role in determining therapeutic responses and in considering tissue collection. ${ }^{72}$ Differences in geography, lifestyle, and diet, along with microbial diversity between individuals and between mucosal versus luminal sites within an individual add another layer of complexity. ${ }^{73-75}$ Existing microbiota can be characterized using metagenomic and metatranscriptomic sequencing $^{74} 75$; however, bacterial contamination and the dynamic relationship between the gut microbiome and immune system complicates this analysis. Obtaining high-quality tissue necessitates tumor cell purification for accurate molecular analysis of the heterogeneous CRC TME and is essential for the success of immuno-oncology clinical trials. Similar to head and neck tissues, addition of antibiotics may be helpful when viable cells need to be derived from gastrointestinal tract tumors.

\section{Pancreatic tissue}

Continued research into the complex biology of pancreatic ductal adenocarcinoma (PDAC) is key to personalizing treatment and improving outcomes. Guidelines exist for standardized procurement of pancreatic tissues. ${ }^{76}$ Clinical trials mainly enroll patients with locally advanced unresectable or metastatic disease. The anatomical location and heterogeneity makes obtaining tissue challenging. ${ }^{77}$ Endoscopic ultrasound is the norm for obtaining fine needle aspirate (FNA) specimens, which are frequently inadequate for meaningful analysis of the TME. The feasibility of getting appropriate DNA quantity is improved in newer studies. ${ }^{78}$ One hundred percent driver gene concordance was noted when comparing FNA to matched tumor tissue identifying different mutations for locally advanced PDAC. Fibrotic reactions around pancreatic tumors are a problem, and laser microdissection is often used to extract tumor cells out of surrounding stromal non-malignant cells. 
Histologically, PDACs have thicker desmoplastic structure than most other cancers with an erratic distribution of lymphoid components. There is minimal to moderate $\mathrm{CD} 3+, \mathrm{CD} 4+$, and $\mathrm{CD} 8+$ T-cell infiltration, predominantly stromally, and metastatic PDACs have lower immune infiltrates compared with resectable primaries. ${ }^{79}$ The TME is immunosuppressive, but functional TILs have been successfully expanded from pancreatic tumors and are able to respond to tumor-associated antigens. ${ }^{80}$ Major issues with pancreatic tissue include the presence of proteases, RNAses, and DNAses, which require expert care and immediate handling in order to maintain quality of planned analytes.

For genomic analysis, high quality, well-annotated tissue repositories are needed. Specimens should be placed in preservative immediately, and transferred rapidly to pathology, ideally within 15 min, to reduce RNA degradation. Minimum sample weight of $200 \mu \mathrm{g}$ is preferred for DNA isolation. Preservation techniques are based on the study intended (eg, flash freezing in liquid nitrogen for RNA and DNA isolation, while FFPE shows better protein structure preservation). Collecting matched peripheral blood samples to isolate germline DNA, as well as serum and pancreatic juice, for future correlation with soluble biomarkers is recommended. ${ }^{81}$ Creation of coordinated clinically annotated regional and national cancer tissue banks is encouraged. ${ }^{82}$ Recently, interest has been generated in research autopsy (a postmortem medical procedure with primary goal of collecting tissue to support basic and translational research) especially to obtain advanced-stage tumor tissue and to facilitate creation of cell lines and PDX models. ${ }^{83}$

\section{Liver tissue}

The liver is an immune organ, with unique components such as Kupffer cells and abundant anticancer effector cells like natural killer (NK) and NK T cells, and a complex relationship exists with chronic inflammation and anticancer immune responses ${ }^{84}$ Few patients qualify for surgical resection and research specimens are hard to come by, mainly obtained from diagnostic biopsies. Many biorepositories and biobanks contain primarily FFPE College of American Pathologists-graduated older samples with corresponding clinical data. Hepatocellular carcinoma is unique due to various mutagenic agents contributing to genomic alterations. ${ }^{85}$ Exome sequencing shows imprints of mutagenic exposures and has identified new genes contributing to tumorigenesis. Protocols to characterize the landscape of pharmacogenomic interactions have discovered gene-drug associations and predictive biomarker candidates. ${ }^{86}$

Core needle biopsies of liver lesions have a high failure rate $(>50 \%)$, mainly due to insufficient tumor content or low RNA yield despite a median of $3 \mathrm{x}$ passes per biopsy and a median of three cores with an average maximum length of $0.7 \mathrm{~cm}$. Liver tissues have high endogenous biotin activity and may simulate positive staining when using a detection method based on biotin labeling, so positive and negative tissue controls have to be used for each antibody. Cold ischemia impacts alterations in RNA transcript levels and protein expression, and significant RNA degradation has been reported after 12 hours. ${ }^{76}$ RNA from FFPE tissue suffers from strand breakage and cross-linking during tissue handing. More than $2000 \mathrm{ng}$ of mRNA is necessary for NGS. ${ }^{87}$

The hepatic TME is enriched with Tregs, tissue resident memory CD8+ T cells, resident NK cells and tumorassociated macrophages. PD- ${ }^{+}$tissue-resident $\mathrm{T}$ cells have been identified as the predominant T-cell subset responsive to anti-PD-1 treatment and were significantly reduced with tumor progression. Using high-dimensional proteomic and transcriptomic analyses, studies showed that an immunosuppressive gradient was identified across the TME, non-TME and peripheral blood in primary HCC that manipulated the activation status of TILs and rendered them immunocompromised against tumor cells. ${ }^{88}$

The rich blood supply of the liver makes it the most common site of visceral metastasis, especially from CRC. The liver TME also provides autocrine and paracrine signals that creates a metastatic niche for tumor growth. Four different phases of liver metastatic development have been described based on both location of cancer cells in the liver parenchyma and phase-dependent interactions between cancer cells and the liver microenvironment ${ }^{89}$; the biological mediators of these phases are potential targets for clinical investigation. Histopathological growth patterns of colorectal metastasis (the specific interface between the tumor and the surrounding normal liver), especially the desmoplastic type associated with the inflamed immune phenotype, could predict efficacy of antiangiogenic therapies in metastatic CRC and may provide a foundation for biomarker analyses of tumor immunotherapy agents in HCC. ${ }^{90}$

\section{Urological tissue}

Despite advances in the treatment of genitourinary malignancies, as a group, they still result in significant cancerrelated mortality worldwide. ${ }^{91}$ Biospecimen collection of genitourinary tissue may be invasive and associated with complications (eg, renal hemorrhage and depletion of tissue). Using alternatives to patient-derived tissue, such as immortalized cell lines, to develop anticancer drugs is discouraging, as they often fail to represent fundamental features of human tumors. ${ }^{92}$ Similarly, the use of two-dimensional monolayer cultures for drug screening and resistance studies has often led to inaccurate results and thus has failed to predict chemoresistance of various tumor types. ${ }^{93}$ There is a growing need to develop patient-derived cell models as these retain patient-specific features and are amenable to a variety of experimental applications, including assessment of genitourinary immunotherapy. ${ }^{94} 95$

Urological tissue should be collected from either biopsy or surgical specimens. Body fluids like urine or blood are collected during routine clinical care activity 
and can be collected for biospecimen banking as well. Blood is often collected as serum, plasma and buffy coats and provides germline data. Although urine can be valuable in order to assess the microbiome and perhaps response to therapy, it has multiple caveats that prevent it being used to adequately sample urological tumors. For one, it may not accurately reflect one particular urological organ (as it could represent the inner lining of the kidney, ureters, bladder, prostatic urethra, and the penile urethra). Second, cellular yield is affected by the time of day and method of collection. Therefore, for organspecific samples, biopsy and surgical specimens are still preferred, but urine may represent a non-invasive future method of sampling.

Special care should be taken in biopsy of primary and metastatic clear cell renal cancers as they are highly vascular and hemorrhage is more common than in other epithelial malignancies. ${ }^{96}$ Urological tissue may be obtained using image guidance, and the reported overall mortality of abdominal fine needle biopsies is only $0.031 \% .^{97}$ Biopsies of some urological tissue (eg, prostate and select bladder specimens) may be performed in the outpatient clinic under a local anesthetic. Prostate biopsies are performed under transrectal/perineal ultrasound guidance, and small bladder biopsies can be performed in the office only if they require minimal to no coagulation. However, most substantial specimens are obtained from the operating room. After collection, the biospecimens must be processed, aliquoted, and frozen in containers suitable for long-term cryopreservation. ${ }^{98}$ Storage at $-80^{\circ} \mathrm{C}$ or in liquid nitrogen freezers is preferable in order to preserve tissue integrity and to avoid repetitive freezing and thawing. ${ }^{99} 100$ The involvement of a pathologist is crucial for gross examination and dissection of the specimen in order to allocate what portion of tissue will be used for routine pathological analysis and the portion that will be used for biobanking. ${ }^{98}$ The majority of tumor tissue will be collected and processed as FFPE tissue blocks. If feasible, tumors can also be collected at the time of procurement and be snap (fresh) frozen for future analysis or placed into OCT media and then frozen (see table 3). Such samples allow molecular analysis and sampling of tumor tissue-infiltrating immune cells (eg, lymphocytes) using a variety of methodologies. Other methods in which viable human tissue may be propagated include the generation of patient-derived cell lines, organoids and xenografts. Similar to other tissues, urological biospecimens are subject to several challenges in biobanking and specimen collection, including cost, patient consent, reporting back of genetic aberrations, ongoing storage and limited specimens for multiple analyses.

\section{Gynecological tissues}

The role of immunotherapy has been shown to be promising in several cancers given its durable response and lower toxicities. However, in gynecological cancer, these results have been underwhelming as monotherapy, except in endometrial cancer with deficient mismatch repair. The response rates in recurrent platinum-resistant ovarian cancer and recurrent endometrial cancer with proficient MMR are low, ranging from $11 \%$ to $15 \%$ compared with up to $53 \%$ in recurrent endometrial cancer with dMMR. ${ }^{101-104}$ Several combination approaches are currently under investigation. Ovarian cancer and the majority of endometrial cancers (except dMMR subtype) are characterized by an immunosuppressive TME and therefore, targeting the immunosuppressive factors within the TME is a potential attractive approach.

To optimize biomarker data, it is important to have rational translational objectives and a standardized approach to collection of gynecological samples (including blood, tissue and ascitic fluid). One approach is to collect these samples at the time of surgery, which will be our focus here. Another approach is to use interventional radiology with image-guided approaches, especially in recurrent settings where surgery is not indicated. At time of surgery, tumor tissue tends to be bulky, especially in patients with ovarian cancer, but it is critical to collect viable tumor with surrounding tissue and avoid necrotic tumor tissue as much as possible. Transferring tissue into culture media might be better than normal saline especially if cell dissociation and single-cell analyses are planned.

Obtaining high-quality tissue is important especially with recent technological advances, such as singlecell RNA sequencing. Tissue obtained at the time of surgery can be immediately processed by dissociating cells, including both tumor cells and tumor-infiltrating immune cells for future analyses using RNA sequencing, single-cell sequencing and/or flow cytometry. Further, ascitic fluid, which is common in ovarian cancer, is an important resource to analyze the TME as it tends to be rich with immune and tumor cells, as well as cytokines. Collection of ascitic fluid can be done not only at the time of surgery but also from patients with recurrent disease with an abdominal catheter placed to drain ascites for palliative symptomatic indications.

\section{Brain and central nervous system (CNS) tissue}

Despite improvements in non-invasive techniques, such as advanced imaging and peripheral blood testing, surgical biopsy remains the gold standard to enable definitive diagnosis and management of CNS lesions. Tumor tissue within the brain can be acquired via a traditional open craniotomy or through the less-invasive stereotactic needle biopsy. Stereotactic needle biopsy is employed most often when lesion diagnosis is the sole goal, and resection is either not indicated or not feasible. This can be true, for instance, in cases of multifocal lesions, suspected small cell lung or lymphoma diagnoses, or in highly eloquent (the primary motor, sensory or visual cortices and their associated fiber tracts) or deep (medulla, pons, midbrain, thalamus and basal ganglia) locations within the brain where an open procedure may put the patient at high risk of postoperative neurological deficits or complications. 
Needle biopsy offers the advantages of small incision size, no craniotomy, theoretical reduced anesthesia time, and ability to target lesions within critical or difficult-to-access locations in the brain. However, it is limited by the size of the needle aspiration port $(\sim 1.0 \times 0.1 \times 0.1 \mathrm{~cm}$, generally requiring aspiration of multiple cores), the lack of direct visualization of the needle tip, and slight inaccuracies inherent to frameless neuronavigation systems, with the resultant potential for sampling error.

For patients presenting with neurological symptoms attributable to mass effect, edema, or hydrocephalus (eg, speech/cognition deficits, motor weakness or neglect, and/or seizures), biopsy alone will not confer rapid symptom resolution or reduction/discontinuation of adjunct therapies, such as corticosteroids. In this scenario, open biopsy via craniotomy plus resection has the advantages of direct visualization of the tissue being obtained (especially useful for small or superficial biopsies), ability to make use of anatomical functional mapping of speech and motor cortices, as well as perform adjunctive tumor debulking or resection for local disease control and symptom relief (with resultant larger tissue yield for histopathologic or research purposes). Downsides to this approach are related to the more invasive nature of the procedure and risks therein (ie, larger incision, removal/ replacement of bone flap, creation of larger corridor to subcortical lesions, and theoretical increased anesthesia time). In rare cases, open biopsy without resection can be used if technical limitations preclude needle biopsy.

Regardless of surgical technique, high resolution MR or CT images should be obtained in the preoperative setting for image guidance. These scans are imported into the neuronavigation software, where trajectory planning and biopsy sampling regions are selected. Major considerations for trajectory planning include incision location (facial avoidance for esthetic reasons), skull angle of entry (as perpendicular of a trajectory as possible to prevent drill skiving), and shortest possible path through the parenchyma that avoids transiting blood vessels, sulci and eloquent or deep brain regions, among others. For lesions that are contrast-enhancing (eg, high-grade gliomas or metastases), sampling is typically targeted to a region of confluent and/or nodular enhancement. For lesions that do not enhance, an intralesional region of T2-weighted-fluid-attenuated inversion recovery (T2/ FLAIR) hyperintensity should be targeted. Necrotic or cystic regions of the lesion should be avoided. This is to maximize the amount of viable, diagnostic tumor tissue, given the expansion in molecular testing performed at most major centers.

\section{Bone tissue}

Tissue banking of primary bone sarcomas presents several unique challenges, and may also apply to metastatic carcinoma to bone for which immunotherapy trials may be valuable. Less than 3500 cases of primary bone sarcoma are diagnosed annually in the USA. Therefore, the rarity of primary bone tumors can lead to reluctance from the pathologist to release tissue for research and banking purposes as tissue supply may be exhausted for diagnostic purposes. Often, once the diagnosis is finalized, small amounts of tissue, if any, remain for banking purposes. This conflict can be further amplified when biopsy specimens are obtained by image-guided needle techniques, which are often performed in hard-to-reach anatomical locations such as the spine and pelvis. The literature supports an average number of five to six core samples (16-18 G) in solid, non-sclerotic soft tissue or bone lesions for diagnosis alone. In sclerotic medullary or cortical bone lesions, a larger gage (commonly $11 \mathrm{G}$ ) is more likely to provide usable tissue. Given the lack of stratifiable biomarkers or actionable targets in bone sarcomas, specimen acquisition exclusively for banking purposes remains controversial.

Most bone sarcomas are treated with preoperative chemotherapy or radiation leading to a paucity of treatment-naive specimens. The standard of care for the treatment of the most common primary bone sarcomas most often consists of preoperative chemotherapy followed by local control. ${ }^{105} 106$ While the post-treatment surgical specimens provide a considerable volume of tissue, therapeutic manipulation likely changes the innate biology. Efforts need to be focused on acquisition of the pretreated tumor and other related correlative specimens (ie, blood and bone marrow).

Mineralized bone often requires decalcification for embedding and sectioning. Demineralization of specimens destroys some of the cellular and extracellular components, thereby rendering the tissue unsuitable for certain techniques, such as ISH or PCR genetic testing. Nucleic acid, in particular, is degraded by the acid demineralization process. In general, routine demineralization of bone specimens should be discouraged. When feasible, tissue should be divided into sections to allow processing of softer elements without decalcification. ${ }^{107}$ One proposed tissue allocation scheme is outlined in table 4.

\section{FUTURE INNOVATIONS IN TISSUE SAMPLING}

While current biospecimen analyses in immunotherapy studies focus on transcriptomic and cellular profiling, new areas of tumor immunology research are expected to result in new assays that may require additional considerations when obtaining tissue. This section provides a brief overview of future directions. Given the extraordinary importance of the host response in cancer and immuno-oncology clinical trials, the ability to sequentially inject, assess responses in the tumor, and examine diversity and clonality of the T-cell and B-cell responses (ie, the adaptome; see figure 2) will be the emergent goals of novel innovations in tissue sampling and evaluation of the primary tumor, nodal draining sites and metastatic sites, focusing on immunity rather than just the tumor itself. $^{108-110}$ 
Table 4 Proposed allocation of bone tissues for various analyses

\begin{tabular}{llll}
\hline Portion of $\mathbf{1} \mathbf{~}^{\mathbf{3}}$ sample (\%) & Cores & Preservation condition & Potential uses \\
\hline 20 & $1-2$ vs touch prep & Frozen section & Confirm viable tissue \\
20 & 2 & FFPE & Histology, IHC, FISH \\
10 & 1 & Flash frozen & RT-PCR \\
20 & $1-2$ & RPMI & Cytogenetics, FISH, flow cytometry \\
30 (when possible) & $2-3$ when possible & Frozen & Banking \\
\hline
\end{tabular}

FFPE, formalin-fixed paraffin-embedded; FISH, Fluorescence in situ hybridization; RPMI, Roswell Park Memorial Institute; RT-PCR, reverse transcription PCR.

\section{Local therapy and assessment of response}

The ability of systemic therapy to mediate important antitumor effects is now well established, adding immunotherapy to chemotherapy and targeted therapy as established therapeutic options. Well within the surgeon and radiation oncologist's bailiwick is the notion of local therapies, allowing development of systemic responses. ${ }^{111} 112$ This has been best developed with the local injection of oncolytic viruses or alternatively immunostimulatory moieties, including TLR9 and STING agonists, developing a local interferon or interleukin-2 signal to promote immune reactivity. These 'pre-tumor-infiltrating lymphocyte' strategies will allow broader application of TIL to other tumor types by recruiting, ${ }^{113}$ even if transiently, T cells that can be sampled and administered to patients, similar to what has been successfully done in the setting of melanoma. ${ }^{114} 115$

\section{Repertoire analysis}

Diversity was originally thought to be due to stochastic processes but now is recognized to be due to combinatorial diversity of encoded germline elements with 'trimming' and N-region diversification (additional nucleotides). ${ }^{116}$ The B-cell receptor is expressed on the surface of B cells with the possibility of generating as many as $10^{26}$ different antibody molecules. ${ }^{117}$ Adult B-cell numbers in any individual are actually $<10^{12}$ cells, with similar numbers predicted of T cells, bearing as many as $10^{15}-10^{25}$ different receptors. ${ }^{118-121}$ Effective immunity to tumors requires an intact adaptive immune system. We

\begin{tabular}{|c|c|c|c|c|c|c|c|c|c|c|c|}
\hline \multicolumn{4}{|c|}{ Patient Response Characteristics } & \multicolumn{7}{c|}{ Repertoire Diversity 50} \\
\hline Response & Tx & $\begin{array}{c}\text { Evans } \\
\text { Grade }\end{array}$ & $\begin{array}{c}\text { DFS } \\
\text { Months }\end{array}$ & $\begin{array}{c}\text { OS } \\
\text { Months }\end{array}$ & Va & V $\boldsymbol{\beta}$ & VY & Vס & IgH & $\operatorname{lgk}$ & $\lg \lambda$ \\
\hline Poor & PG & I & 3.3 & 3.3 & 20.4 & 19 & n/a & 50 & 1.3 & 0.5 & 1.1 \\
\hline Good & PGH & IIB & 39.6 & 42.3 & 25 & 26.8 & n/a & 33.3 & 0.4 & 0.4 & 0.1 \\
\hline
\end{tabular}

B

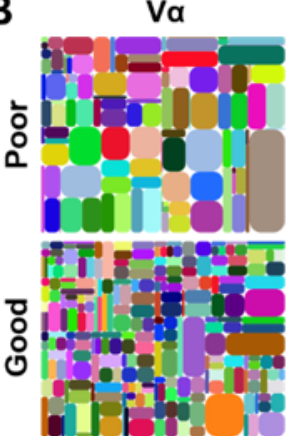

\section{$\mathrm{V} \beta$}

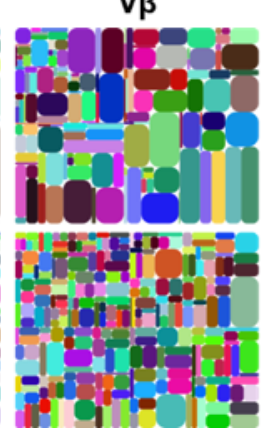

Vס

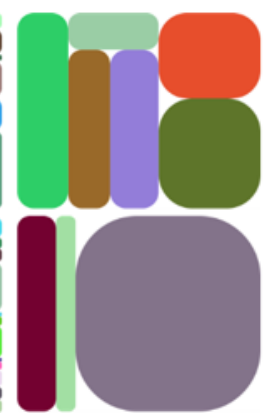

$\lg \mathrm{H}$

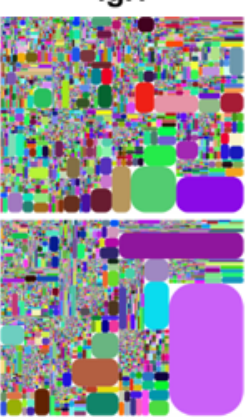

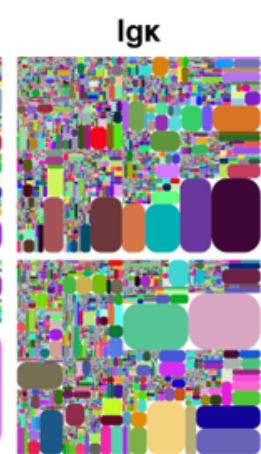

$\lg \lambda$

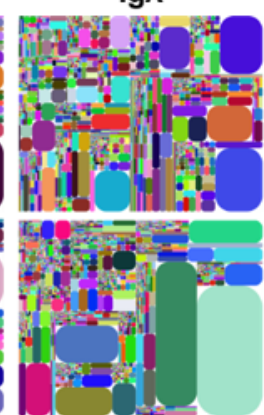

Figure 2 T-cell and B-cell repertoire diversity of resected pancreatic cancer tumor following neoadjuvant therapy. Patients with resectable pancreatic cancer were randomized for preoperative nab-PG alone or with autophagy inhibition (PGH). DAM-PCR and NGS of resected pancreatic tumor FFPE tissue were completed to evaluate the influence of T-cell and B-cell receptor diversity on clinical outcome. (A) Shown are two representative poor and good responding patients with Evans grade pathological non-response (I, <10\% tumor destruction) and partial response (IIB, 51\%-90\% tumor destruction) as determined by a blinded surgical pathologist, with corresponding DFS, OS, and seven-chain repertoire Diversity 50 (the percent of dominant and unique T-cell or B-cell clones that account for the cumulative top $50 \%$ of the total reads in a sample). Limited $\mathrm{V} \gamma$ expression precluded $\mathrm{V} \gamma$ diversity analysis. (B) Resected tumor adaptome diversity tree maps of chains from selected patients. Each rounded rectangle represents a unique CDR3, with the size of the rectangle corresponding to the relative frequency of the CDR3 clones across the entire distribution. ${ }^{125}$ DAM-PCR, dimer avoidance multiplex PCR; DFS, disease-free survival; FFPE, formalinfixed paraffin-embedded; NGS, next-generation sequencing; OS, overall survival; PG, paclitaxel and gemcitabine, PGH, nabpaclitaxel, gemcitabine and hydroxychloroquine. 
Table 5 Major considerations in biospecimen collection and handling reported by the Society for Immunotherapy of Cancer Surgery Committee

\begin{tabular}{lll}
\hline Prior to biopsy & During collection & After collection \\
\hline Early consultation with surgical or & Ensure that all supplies and collection & Ensure rapid delivery to \\
interventional physician expertise & containers are available & laboratory, if appropriate \\
Early consultation with surgical & Once tissue is obtained, processing & Rapid shipping with proper \\
pathologist to plan specimen allocation & should be as rapid as possible & labels and addresses
\end{tabular}

Therapeutic immune cell collection

and testing (ie, SOC vs research)

Ensure IRB approval and written Ensure enough tissue is obtained,

informed consent are obtained prior to especially if required for SOC the procedure

\section{Establish SOPs for specimen collection at institution}

\begin{abstract}
Ensure that all personnel involved in tissue collection are trained in local SOPs
\end{abstract}

Consider the number of cells and viability status needed from tissue; consult with immunology experts to define

\section{Consider preservatives needed to Use new supplies and containers for process and store tissue once collected each new specimen}

Consider if matched specimens are needed (ie, PBMC and tumor) at each time point

$\begin{array}{lll}\text { If sample not fixed immediately, } & \text { If processing is delayed, } & \begin{array}{l}\text { Confirm days and times } \\ \text { consider vacuum sealing, placing in } \\ \text { sterile gauze with preservative fluid, or }\end{array} \\ \begin{array}{ll}\text { on ice in sterile system } & \text { unless otherwise indicated }\end{array} & \begin{array}{l}\text { open for specimen } \\ \text { receiving prior to } \\ \text { procedure }\end{array}\end{array}$

If a biosafety cabinet is not available, establish a "clean" area for initial specimen handling

Avoid contact between different specimens
Sterile conditions must be used throughout

Ensure all processing and shipping SOPs are in place

Monitor the temperature of Work with clinical collected specimens prior to processing and avoid excessive heat

immunotherapy experts to ensure appropriate patients and lesions are selected

Confirm days and times procedure

\section{Determine the type of biopsy (eg, core needle, incisional, excisional, etc.) to be done and what instruments and reagents (eg, needles, collection bottles, preservatives, etc.) are needed}

Understand institutional policies and regulations, including coordination with pathology for SOC

\section{Ensure pre-labeling of all specimen} containers and patient materials

Consider using a time tracking process with documentation

\section{Consider collecting normal tissues as} control

IRB, institutional review board; PBMC, peripheral blood mononuclear cell; SOC, standard of care; SOP, standard operating procedure.

have made great progress in allowing assessment of the complexity of the T-cell receptor (TCR) repertoire in patients undergoing immunotherapy. ${ }^{122}$ A deep understanding of the breadth and depth of the immune repertoire has only come about as a consequence of modern technologies capable of assessing each of the now apparent rearranged receptors in totality. We should plan to carefully examine starting cell populations (from the tumor) and paired peripheral blood prior to, during and sequentially following therapy to examine the evolution of an immune response. Analysis of maturation markers, exhaustion markers, and expression of T-cell, NK and B-cell markers, as well as baseline diversity measures may provide valuable insight. The ability to sequentially harvest spatially distinct regions of the tissue/tumor will be increasingly important in the personalized evaluation of an individual's own tumor.

\section{Integration of tumor tissue biopsy and blood 'liquid biopsy' biospecimens}

Tumor-reactive and neoantigen-reactive TCRs can be identified based on their frequency in the tumor by TCR 
sequencing without knowledge of cognate epitopes, and can be exploited for developing personalized neoantigenbased vaccines or TCR-gene therapy. ${ }^{123}$ TCR sequencing of both tumor tissue and peripheral blood allows us to identify TIL clonotypes (TIL-TCRs, both alpha beta and gamma delta), as well as B cells (IgH chain and kappa and lambda light chains) within the tumor and peripheral blood. The frequency of circulating TIL-TCRs can be monitored over the course of treatment to evaluate response to immunotherapy. ${ }^{124}$ Furthermore, highdimensional single-cell profiling platforms (eg, 10× chromium) have been transformative for understanding complex cell populations. Combining TCR and scRNAseq should allow us to profile paired TCR $\alpha \beta$ sequences, cellular proteins, gene function, and transcriptional signatures, and to identify novel transcriptional, genomic, and cellular markers of clonally expanded TIL-TCRs in peripheral blood, unveiling mechanisms of response and resistance to immunotherapy.

\section{CONCLUSIONS AND RECOMMENDATIONS}

Tumor immunotherapy has revolutionized the treatment of patients with a wide range of cancers over the past decade. These advances have relied on access to peripheral blood, tumor tissue and other body tissue (eg, tissue involved with immune-related adverse side effects). The optimal methods for tissue access, processing, handling and storage have received little attention and many biomarkers have failed large-scale validation, at least in part due to wide differences in the collection and processing of tissues across different clinical and laboratory sites. Finally, while there are important anatomical and physiological considerations, most locations are accessible by direct or image-guided approaches. Surgical and interventional subspecialists may provide additional support in accessing tissue in complicated locations. Most of the general recommendations herein are uniformly applicable to biospecimen collection from any anatomical site and are summarized in table 5. In particular, the SITC Surgery Committee recommends inclusion of a surgical oncologist, surgical subspecialist, or interventional physician when planning tissue specimen immunotherapy studies in patients with cancer, and early communication and coordination with local surgical pathologists.

\section{Author affiliations}

${ }^{1}$ Department of Plastic Surgery, Cleveland Clinic, Cleveland, Ohio, USA

${ }^{2}$ Department of Surgery, University of Chicago, Chicago, Illinois, USA

${ }^{3}$ Division of Surgical Oncology, Rutgers Cancer Institute of New Jersey, New

Brunswick, New Jersey, USA

${ }^{4}$ Department of Surgical Oncology, Massachusetts General Hospital, Boston, Massachusetts, USA

${ }^{5}$ Oncology, Johns Hopkins Medicine Sidney Kimmel Comprehensive Cancer Center, Baltimore, Maryland, USA

${ }^{6}$ Department of Surgery, Johns Hopkins Medicine, Baltimore, Maryland, USA

${ }^{7}$ Parker Institute for Cancer Immunotherapy, San Francisco, California, USA

${ }^{8}$ Microbiology and Immunology, University of California San Francisco, San

Francisco, California, USA

${ }^{9}$ Department of Surgery, University of Washington, Seattle, Washington, USA
${ }^{10}$ Department of Neurosurgery, Duke University School of Medicine, Durham, North Carolina, USA

${ }^{11}$ Departments of Otolaryngology, Immunology, and Radiation Oncology, University of Pittsburgh Hillman Cancer Center, Pittsburgh, Pennsylvania, USA

${ }^{12}$ Department of Surgery, City of Hope National Medical Center, Duarte, California, USA

${ }^{13} \mathrm{NCl} / \mathrm{SB}$, National Cancer Institute, Bethesda, Maryland, USA

${ }^{14}$ Department of Neurosurgery, Duke Center for Brain and Spine Metastasis, Durham, North Carolina, USA

${ }^{15}$ Center for Immunotherapy, Department of Surgical Oncology, Roswell Park Comprehensive Cancer Center, Buffalo, New York, USA

${ }^{16}$ Departments of Neurosurgery, Oncology, Radiation Oncology, and Otolaryngology, Johns Hopkins University School of Medicine, Baltimore, Maryland, USA

${ }^{17}$ Department of Surgery, University of Pittsburgh School of Medicine, Pittsburgh,

Pennsylvania, USA

${ }^{18}$ OBGYN and Women's Health Institute, Cleveland Clinic, Cleveland, Ohio, USA

${ }^{19}$ Department of Gastrointestinal Oncology, Moffitt Cancer Center, Tampa, Florida, USA

${ }^{20}$ Division of Orthopaedic Oncology, Johns Hopkins University, Baltimore, Maryland, USA

${ }^{21}$ Department of Surgery, UPMC Hillman Cancer Center, University of Pittsburgh, Pittsburgh, Pennsylvania, USA

${ }^{22}$ Department of Surgery, Penn State Cancer Institute, Hershey, Pennsylvania, USA

${ }^{23}$ Departments of Immunology and Gynecologic Oncology, Roswell Park Cancer Institute, Buffalo, New York, USA

${ }^{24}$ Division of Surgical Oncology, Department of Surgery, UNM Comprehensive Cancer Center, University of New Mexico, Albuquerque, New Mexico, USA

${ }^{25}$ Surgery Branch, National Cancer Institute, Bethesda, Maryland, USA

${ }^{26}$ Department of Surgery, University of Chicago Hospitals, Chicago, Illinois, United States

${ }^{27}$ Nurix Therapeutics Inc, San Francisco, California, USA

${ }^{28}$ Departments of Surgical Oncology and Immunology, Roswell Park Comprehensive Cancer Center, Buffalo, New York, USA

${ }^{29}$ Department of Surgery, Division of Surgical Oncology, Breast and Melanoma Surgery, University of Virginia, Charlottesville, Virginia, USA

${ }^{30}$ Department of Cutaneous Oncology, Moffitt Cancer Center, Tampa, Florida, USA

${ }^{31}$ Department of Otolaryngology, Stanford University School of Medicine, Stanford, California, USA

${ }^{32}$ Surgery Department, Centre Hospitalier de I'Universite de Montreal, Montreal, Quebec, Canada

${ }^{33}$ Department of Pathology, Fred Hutchinson Cancer Research Center, Seattle, Washington, USA

${ }^{34}$ Immuneering Corp, Cambridge, Massachusetts, USA

\section{Twitter Robert L Ferris @robertferrismd}

Acknowledgements The authors acknowledge SITC staff for their contributions, including Emily B Shepard, PhD, for medical writing and editorial support, and Matthew Erickson for project management and assistance. Additionally, the authors wish to thank the society for supporting the manuscript development.

Contributors BG and HLK provided leadership and guidance on the manuscript structure and content, as well as drafted substantial content. All other authors equally drafted content and provided critical review during the manuscript development process and are therefore listed in alphabetical order. All authors have read and approved the final version of this article.

Funding This manuscript was funded by the Society for Immunotherapy of Cancer

Competing interests BG is a consultant for Quest Imaging and a speaker for Castle Biosciences. PKA has partner salary from Pfizer. GB has sponsored research agreements with Takeda Oncology, Olink Proteomics, and Palleon, honorarium from Novartis, and consulting for NW Biotherapeutics. SB is a consultant for BMS. LHB is a consultant for Stemlmmune/Calidi, NextCure, Replimmune, Western Oncolytics, Torque Therapeutics, Khloris, Pyxis, Cytomix, and Roche-Genentech. PEF is a consultant for Monteris Medical. RLF is a consultant for Aduro Biotech, Amgen, Astra-Zeneca/Medimmune, Bain Capital Life Sciences, BMS, EMD Serono, GSK, Iovance, Lilly, MacroGenics, Merck, Nanobiotx, Numab Therapeutics, Oncorus, Ono Pharmaceutcal Co., Pfizer, PPD, Regeneron, Tesaro, Torque Therapeutics, TTMS, and VentiRx Pharmaceuticals; has contracted research agreements with Astra-Zeneca/Medimmune, BMS, Merck, Tesaro, and TTMS, has partner consulting for Janssen, Lilly, Scibase, DermTech, BMS, and Pfizer, and has partner contracted 
research agreements with Regeneron, Janssen, BMS, Abbvie, BI, Castle Biosciences and Lilly.YF has relationships with Imagene, Merck, Eureka and Surgamo, and partner interest in Pfizer. MLim is a consultant for Tocagen, VBI and Strykes, and receives research funding from Arbor, BMS and Biohaven. MLotze receives salary from Nurix, Inc., royalty from Cellatrope, has IP rights in Intrexon, consults for Myst, Instill, Checkmate, Carisma and Surface Oncology, and has ownership interest in iRepertoire. HM has contracted research with Puma Biotechnology. RIN is a consultant for Novartis, Castle Biosciences, and Sanofi-Granzyme and has contracted research with Regeneron and Castle Biosciences. A0 is a cofounder of Tactiva Therapeutics, Inc., and receives research support from AstraZeneca and Tesaro. SP is a consultant for Abbvie, Astra-Zeneca, Cue Biopharma, Fusion Biopharma, Merck, Newlink Genetics, Oncolys Biopharma, Oncosec, Replimmune and Sensei Bio, contracted research with Abbvie, Astra-Zeneca, Cue Biopharma, Sensei Bio and Tesaro, and investigator-initiated trials with ASTX Pharmaceuticals, Astra-Zeneca, Cue Biopharma, ImmuneDesign and Merck. SAR has patents held by the $\mathrm{NCl}$ and cooperative research agreements with Kite, lovance and Ziopharm. CLS is a consultant for Celldex, CureVac and Castle Biosciences, and has institutional support from Celldex, Polynoma, GSK, Merck, 3M, Theraclion and Immatics. VKS is a consultant for Array, BMS, Merck, Novartis, Pfizer, Polynoma, Regeneron and Replimmune. JBS is on the advisory board of ABL Bio and is the scientific founder of Indapta Therapeutics. ST is a consultant for TVM Life Science, received honoraria from Astra-Zeneca, Celgene and Exactis Innovation, and has research grants from BMS and lovance. CY is a consultant for Loxo, Merck and Adaptive Biotechnologies, has contracted research with Obi and Pfizer, and has ownership interest in Molpath Dx, LLC. HLK is an employee of Immuneering Coporation.

\section{Patient consent for publication Not required.}

Provenance and peer review Not commissioned; externally peer reviewed.

Supplemental material This content has been supplied by the author(s). It has not been vetted by BMJ Publishing Group Limited (BMJ) and may not have been peer-reviewed. Any opinions or recommendations discussed are solely those of the author(s) and are not endorsed by BMJ. BMJ disclaims all liability and responsibility arising from any reliance placed on the content. Where the content includes any translated material, BMJ does not warrant the accuracy and reliability of the translations (including but not limited to local regulations, clinical guidelines, terminology, drug names and drug dosages), and is not responsible for any error and/or omissions arising from translation and adaptation or otherwise.

Open access This is an open access article distributed in accordance with the Creative Commons Attribution Non Commercial (CC BY-NC 4.0) license, which permits others to distribute, remix, adapt, build upon this work non-commercially, and license their derivative works on different terms, provided the original work is properly cited, appropriate credit is given, any changes made indicated, and the use is non-commercial. See http://creativecommons.org/licenses/by-nc/4.0/.

\section{ORCID iDs}

Genevieve Boland http://orcid.org/0000-0002-7522-6173

Lisa H Butterfield http://orcid.org/0000-0002-3439-9844

Stephanie L Goff http://orcid.org/0000-0003-3317-9804

Rogerio I Neves http://orcid.org/0000-0003-4866-5215

Craig L Slingluff http://orcid.org/0000-0002-6664-4373

\section{REFERENCES}

1 Galluzzi L, Chan TA, Kroemer G, et al. The hallmarks of successful anticancer immunotherapy. Sci Trans/ Med 2018;10:eaat7807.

2 Lantuejoul S, Sound-Tsao M, Cooper WA, et al. PD-L1 testing for lung cancer in 2019: perspective from the IASLC pathology Committee. J Thorac Oncol 2020;15:499-519.

3 Masucci GV, Cesano A, Hawtin R, et al. Validation of biomarkers to predict response to immunotherapy in cancer: Volume I - preanalytical and analytical validation. J Immunother Cancer 2016;4:76.

4 Gnjatic S, Bronte V, Brunet LR, et al. Identifying baseline immunerelated biomarkers to predict clinical outcome of immunotherapy. $J$ Immunother Cancer 2017;5:44.

5 Boscolo-Berto R, Macchi V, Porzionato A, et al. Editorial for "Preoperative Assessment for High-Risk Endometrial Cancer by Developing an MRI- and Clinical-Based Radiomics Nomogram: A Multicenter Study". J Magn Reson Imaging 2020:e27287.

6 Chen $\mathrm{H}, \mathrm{He} \mathrm{Y}$, Zhao C, et al. Reproducibility of radiomics features derived from intravoxel incoherent motion diffusion-weighted MRI of cervical cancer. Acta Radiol 2020:284185120934471.

7 Chu LC, Solmaz B, Park S, et al. Diagnostic performance of commercially available vs. in-house radiomics software in classification of CT images from patients with pancreatic ductal adenocarcinoma vs. healthy controls. Abdom Radiol 2020;45:2469-75.

8 Khene Z-E, Mathieu R, Peyronnet B, et al. Radiomics can predict tumour response in patients treated with nivolumab for a metastatic renal cell carcinoma: an artificial intelligence concept. World J Urol 2020. doi:10.1007/s00345-020-03334-5. [Epub ahead of print: 06 Jul 2020].

9 Shiri I, Maleki H, Hajianfar G, et al. Next-Generation Radiogenomics sequencing for prediction of EGFR and KRAS mutation status in NSCLC patients using multimodal imaging and machine learning algorithms. Mol Imaging Biol 2020;22:1132-48.

10 Sudre $\mathrm{CH}$, Panovska-Griffiths J, Sanverdi E, et al. Machine learning assisted DSC-MRI radiomics as a tool for glioma classification by grade and mutation status. BMC Med Inform Decis Mak 2020;20:149.

11 Goodman AM, Kato S, Bazhenova L, et al. Tumor mutational burden as an independent predictor of response to immunotherapy in diverse cancers. Mol Cancer Ther 2017; 16:2598-608.

12 Samstein RM, Lee C-H, Shoushtari AN, et al. Tumor mutational load predicts survival after immunotherapy across multiple cancer types. Nat Genet 2019;51:202-6.

13 Robbins PF, Lu Y-C, El-Gamil M, et al. Mining exomic sequencing data to identify mutated antigens recognized by adoptively transferred tumor-reactive T cells. Nat Med 2013;19:747-52.

14 Parkhurst MR, Robbins PF, Tran E, et al. Unique neoantigens arise from somatic mutations in patients with gastrointestinal cancers. Cancer Discov 2019;9:1022-35.

15 Malekzadeh P, Pasetto A, Robbins PF, et al. Neoantigen screening identifies broad TP53 mutant immunogenicity in patients with epithelial cancers. J Clin Invest 2019;129:1109-14.

16 Tran E, Turcotte S, Gros A, et al. Cancer immunotherapy based on mutation-specific CD4+ T cells in a patient with epithelial cancer. Science 2014;344:641-5

17 Tran E, Robbins PF, Lu Y-C, et al. T-Cell transfer therapy targeting mutant KRAS in cancer. N Engl J Med 2016;375:2255-62.

18 Stevanović S, Pasetto A, Helman SR, et al. Landscape of immunogenic tumor antigens in successful immunotherapy of virally induced epithelial cancer. Science 2017;356:200-5.

19 Zacharakis N, Chinnasamy H, Black M, et al. Immune recognition of somatic mutations leading to complete durable regression in metastatic breast cancer. Nat Med 2018;24:724-30.

20 Hodi FS, Minm MC, Soiffer RJ, et al. Biologic activity of cytotoxic T lymphocyte-associated antigen 4 antibody blockade in previously vaccinated metastatic melanoma and ovarian carcinoma patients. Proc Natl Acad Sci U S A 2003;100:4712-7.

21 Phan GQ, Yang JC, Sherry RM, et al. Cancer regression and autoimmunity induced by cytotoxic $\mathrm{T}$ lymphocyte-associated antigen 4 blockade in patients with metastatic melanoma. Proc Nat Acad Sci U S A 2003;100:8372-7.

22 Beck KE, Blansfield JA, Tran KQ, et al. Enterocolitis in patients with cancer after antibody blockade of cytotoxic T-lymphocyteassociated antigen 4. J Clin Oncol 2006;24:2283-9.

23 Carrick DM, Mehaffey MG, Sachs MC, et al. Robustness of next generation sequencing on older formalin-fixed paraffin-embedded tissue. PLoS One 2015;10:e0127353.

24 Groelz D, Viertler C, Pabst D, et al. Impact of storage conditions on the quality of nucleic acids in paraffin embedded tissues. PLoS One 2018;13:e0203608.

25 Kokkat TJ, Patel MS, McGarvey D, et al. Archived formalin-fixed paraffin-embedded (FFPE) blocks: a valuable underexploited resource for extraction of DNA, RNA, and protein. Biopreserv Biobank 2013;11:101-6.

26 Levin Y, Talsania K, Tran B, et al. Optimization for sequencing and analysis of degraded FFPE-RNA samples. J Vis Exp 2020;160:e61060.

27 Smith CC, Bixby LM, Miller KL, et al. Using RNA sequencing to characterize the tumor microenvironment. In: Thurin $\mathrm{M}$, Cesano A, Marincola FM, et al, eds. Biomarkers for immunotherapy of cancer: methods and protocols. New York, NY: Springer New York, 2020: 245-72.

28 Sade-Feldman M, Yizhak K, Bjorgaard SL, et al. Defining T cell states associated with response to checkpoint immunotherapy in melanoma. Cell 2019;176:404.

29 Habib N, Avraham-Davidi I, Basu A, et al. Massively parallel single-nucleus RNA-seq with DroNc-seq. Nat Methods 2017;14:955-8.

30 Habib N, Li Y, Heidenreich M, et al. Div-Seq: Single-nucleus RNAseq reveals dynamics of rare adult newborn neurons. Science 2016;353:925-8. 
31 Goltsev Y, Samusik N, Kennedy-Darling J, et al. Deep profiling of mouse splenic architecture with Codex multiplexed imaging. Cell 2018;174:968-81. e15.

32 Lin J-R, Izar B, Wang S, et al. Highly multiplexed immunofluorescence imaging of human tissues and tumors using t-CyCIF and conventional optical microscopes. elife 2018;7.

33 Lee JH, Daugharthy ER, Scheiman J, et al. Fluorescent in situ sequencing (FISSEQ) of RNA for gene expression profiling in intact cells and tissues. Nat Protoc 2015;10:442-58.

34 Wang Y, Woehrstein JB, Donoghue N, et al. Rapid sequential in situ multiplexing with DNA exchange imaging in neuronal cells and tissues. Nano Lett 2017;17:6131-9.

35 Butterfield LH. The Society for immunotherapy of cancer biomarkers Task force recommendations review. Semin Cancer Biol 2018;52:12-15.

36 Slingluff CL, Petroni GR, Molhoek KR, et al. Clinical activity and safety of combination therapy with temsirolimus and bevacizumab for advanced melanoma: a phase II trial (CTEP 7190/Mel47). Clin Cancer Res 2013;19:3611-20.

37 Riaz N, Havel JJ, Makarov V, et al. Tumor and microenvironment evolution during immunotherapy with nivolumab. Cell 2017;171:934-49. e15.

38 Tetzlaff MT, Messina JL, Stein JE, et al. Pathological assessment of resection specimens after neoadjuvant therapy for metastatic melanoma. Ann Oncol 2018;29:1861-8.

39 Olson WC, Smolkin ME, Farris EM, et al. Shipping blood to a central laboratory in multicenter clinical trials: effect of ambient temperature on specimen temperature, and effects of temperature on mononuclear cell yield, viability and immunologic function. J Transl Med 2011;9:26.

40 Judge JM, Chianese-Bullock KA, Schroen AT, et al. Usefulness of prestudy assessment of patient willingness to undergo tissue biopsy for correlative studies in a melanoma vaccine trial. Clin Trials 2013;10:143-50.

41 Meslin EM, Quaid KA. Ethical issues in the collection, storage, and research use of human biological materials. J Lab Clin Med 2004;144:229-34. discussion 6.

42 Amaria RN, Reddy SM, Tawbi HA, et al. Neoadjuvant immune checkpoint blockade in high-risk resectable melanoma. Nat Med 2018;24:1649-54

43 Jabbar K, Routbort M, Singh C, et al. Impact of tumor necrosis on success of clinical next generation sequencing. Mod Pathol 2015;28.

44 Slingluff CL, Yamshchikov GV, Hogan KT, et al. Evaluation of the sentinel immunized node for immune monitoring of cancer vaccines. Ann Surg Oncol 2008:15:3538-49.

45 Cheung Y-C, Chang JW-C, Hsieh J-J, et al. Adequacy and complications of computed tomography-guided core needle biopsy on non-small cell lung cancers for epidermal growth factor receptor mutations demonstration: 18-gauge or 20-gauge biopsy needle. Lung Cancer 2010;67:166-9.

46 Thunnissen E, Kerr KM, Dafni U, et al. Programmed death-ligand 1 expression influenced by tissue sample size. scoring based on tissue microarrays' and cross-validation with resections, in patients with, stage I-III, non-small cell lung carcinoma of the European thoracic oncology platform Lungscape cohort. Mod Pathol 2020;33:792-801.

47 Payne Ondracek R, Cheng J, Gangavarapu KJ, et al. Impact of devascularization and tissue procurement on cell number and RNA integrity in prostatectomy tissue. Prostate 2015;75:1910-5.

48 Compton CC, Robb JA, Anderson MW, et al. Preanalytics and precision pathology: pathology practices to ensure molecular integrity of cancer patient biospecimens for precision medicine. Arch Pathol Lab Med 2019;143:1346-63.

49 Allison $\mathrm{KH}$, Hammond MEH, Dowsett M, et al. Estrogen and progesterone receptor testing in breast cancer: American Society of clinical Oncology/College of American pathologists guideline update. Arch Pathol Lab Med 2020;144:545-63.

50 Brahmer J, Reckamp KL, Baas P, et al. Nivolumab versus docetaxel in advanced squamous-cell non-small-cell lung cancer. $N$ Engl $J$ Med 2015;373:123-35

51 Borghaei $\mathrm{H}$, Paz-Ares L, Horn L, et al. Nivolumab versus docetaxel in advanced Nonsquamous non-small-cell lung cancer. $N$ Engl $J$ Med 2015;373:1627-39.

52 Herbst RS, Baas P, Kim D-W, et al. Pembrolizumab versus docetaxel for previously treated, PD-L1-positive, advanced nonsmall-cell lung cancer (KEYNOTE-010): a randomised controlled trial. Lancet 2016;387:1540-50.

53 Fehrenbacher L, Spira A, Ballinger M, et al. Atezolizumab versus docetaxel for patients with previously treated non-small-cell lung cancer (poplar): a multicentre, open-label, phase 2 randomised controlled trial. Lancet 2016;387:1837-46.
54 Rittmeyer A, Barlesi F, Waterkamp D, et al. Atezolizumab versus docetaxel in patients with previously treated non-small-cell lung cancer (OAK): a phase 3, open-label, multicentre randomised controlled trial. Lancet 2017:389:255-65.

55 Reck M, Rodríguez-Abreu D, Robinson AG, et al. Pembrolizumab versus chemotherapy for PD-L1-positive non-small-cell lung cancer. N Engl J Med 2016;375:1823-33.

56 Gandhi L, Rodríguez-Abreu D, Gadgeel S, et al. Pembrolizumab plus chemotherapy in metastatic non-small-cell lung cancer. $N$ Engl J Med 2018:378:2078-92.

57 Forde PM, Chaft JE, Smith KN, et al. Neoadjuvant PD-1 blockade in resectable lung cancer. N Engl J Med 2018;378:1976-86.

58 Bott MJ, Yang SC, Park BJ, et al. Initial results of pulmonary resection after neoadjuvant nivolumab in patients with resectable non-small cell lung cancer. J Thorac Cardiovasc Surg 2019;158:269-76.

59 Rusch VW, Chaft JE, Johnson B, et al. Neoadjuvant atezolizumab in resectable non-small cell lung cancer (NSCLC): initial results from a multicenter study (LCMC3). J Clin Oncol 2018;36:8541.

60 Provencio $M$, Nadal $E$ Insa $A$, et al. Neoadiuvant chemoimmunotherapy for the treatment of stage IIIA resectable nonsmall-cell lung cancer (NSCLC): a phase II multicenter exploratory study-Final data of patients who underwent surgical assessment. JCO 2019;37:8509.

61 Cascone T, William WN, Weissferdt A, et al. Neoadjuvant nivolumab (N) or nivolumab plus ipilimumab (NI) for resectable non-small cell lung cancer (NSCLC). Ann Oncol 2018;29:viii738.

62 Travis WD, Dacic S, Wistuba I, et al. IASLC multidisciplinary recommendations for pathologic assessment of lung cancer resection specimens after neoadjuvant therapy. $J$ Thorac Oncol 2020;15:709-40.

63 Overman MJ, Lonardi S, Wong KYM, et al. Durable clinical benefit with nivolumab plus ipilimumab in DNA mismatch Repair-Deficient/ Microsatellite Instability-High metastatic colorectal cancer. J Clin Oncol 2018;36:773-9.

64 Overman MJ, McDermott R, Leach JL, et al. Nivolumab in patients with metastatic DNA mismatch repair-deficient or microsatellite instability-high colorectal cancer (CheckMate 142): an open-label, multicentre, phase 2 study. Lancet Oncol 2017:18:1182-91.

65 Pang S-W, Awi NJ, Armon S, et al. Current update of laboratory molecular diagnostics advancement in management of colorectal cancer (CRC). Diagnostics 2020;10:9

66 Ludford K, Cohen R, Svrcek M, et al. Pathological tumor response following immune checkpoint blockade for deficient mismatch repair advanced colorectal cancer. J Natl Cancer Inst 2020. doi:10.1093/jnci/djaa052. [Epub ahead of print: 15 Apr 2020].

67 Chalabi M, Fanchi LF, Dijkstra KK, et al. Neoadjuvant immunotherapy leads to pathological responses in MMRproficient and MMR-deficient early-stage colon cancers. Nat Med 2020;26:566-76.

68 Nagler-Anderson C. Man the barrier! strategic defences in the intestinal mucosa. Nat Rev Immunol 2001;1:59-67.

69 Zeuner A, Todaro M, Stassi G, et al. Colorectal cancer stem cells: from the crypt to the clinic. Cell Stem Cell 2014;15:692-705.

70 Chen F, Zhuang X, Lin L, et al. New horizons in tumor microenvironment biology: challenges and opportunities. BMC Med 2015;13:45.

71 Itzkowitz SH, Yio X. Inflammation and cancer IV. Colorectal cancer in inflammatory bowel disease: the role of inflammation. $A m J$ Physiol Gastrointest Liver Physiol 2004;287:G7-17.

72 Swami U, Zakharia Y, Zhang J. Understanding microbiome effect on immune checkpoint inhibition in lung cancer: placing the puzzle pieces together. J Immunother 2018;41:359-60.

73 Gopalakrishnan V, Helmink BA, Spencer CN, et al. The influence of the gut microbiome on cancer, immunity, and cancer immunotherapy. Cancer Cell 2018;33:570-80.

74 Fessler J, Matson V, Gajewski TF. Exploring the emerging role of the microbiome in cancer immunotherapy. J Immunother Cancer 2019;7:108.

75 Schwabe RF, Jobin C. The microbiome and cancer. Nat Rev Cancer 2013;13:800-12.

$76 \mathrm{NCl}$ best practices for Biospecimen resources.

77 Sjoquist KM, Chin VT, Chantrill LA, et al. Personalising pancreas cancer treatment: when tissue is the issue. World J Gastroenterol 2014;20:7849-63.

78 Valero V, Saunders TJ, He J, et al. Reliable detection of somatic mutations in fine needle aspirates of pancreatic cancer with nextgeneration sequencing: implications for surgical management. Ann Surg 2016;263:153-61.

79 Blando J, Sharma A, Higa MG, et al. Comparison of immune infiltrates in melanoma and pancreatic cancer highlights VISTA as 
a potential target in pancreatic cancer. Proc Natl Acad Sci U S A 2019;116:1692-7.

80 Hall M, Liu H, Malafa M, et al. Expansion of tumor-infiltrating lymphocytes (TIL) from human pancreatic tumors. J Immunother Cancer 2016;4:61.

81 Voidonikolas G, Gingras M-C, Hodges S, et al. Developing a tissue resource to characterize the genome of pancreatic cancer. World $\mathrm{J}$ Surg 2009;33:723-31.

82 Balarajah V, Ambily A, Dayem Ullah AZ, et al. Pancreatic cancer tissue banks: where are we heading? Future Oncol 2016;12:2661-3.

83 lacobuzio-Donahue CA, Michael C, Baez P, et al. Cancer biology as revealed by the research autopsy. Nat Rev Cancer 2019;19:686-97.

84 Keenan BP, Fong L, Kelley RK. Immunotherapy in hepatocellular carcinoma: the complex interface between inflammation, fibrosis, and the immune response. J Immunother Cancer 2019;7:267.

85 Zhang Z. Genomic landscape of liver cancer. Nat Genet 2012;44:1075-7.

86 Qiu Z, Li H, Zhang Z, et al. A pharmacogenomic landscape in human liver cancers. Cancer Cell 2019;36:179-93. e11.

87 Lee K, Lee SJ, Yoon S, et al. Feasibility, safety, and adequacy of research biopsies for cancer clinical trials at an academic medical center. PLoS One 2019;14:e0221065.

88 Chew V, Lai L, Pan L, et al. Delineation of an immunosuppressive gradient in hepatocellular carcinoma using high-dimensional proteomic and transcriptomic analyses. Proc Natl Acad Sci U S A 2017:114:E5900-9.

89 Milette S, Sicklick JK, Lowy AM, et al. Molecular pathways: targeting the microenvironment of liver metastases. Clin Cancer Res 2017;23:6390-9.

90 Stremitzer S, Vermeulen P, Graver S, et al. Immune phenotype and histopathological growth pattern in patients with colorectal liver metastases. Br J Cancer 2020;122:1518-24.

91 Siegel RL, Miller KD, Jemal A. Cancer statistics, 2019. CA A Cancer $J$ Clin 2019:69:7-34.

92 Bolck HA, Pauli C, Göbel E, et al. Cancer sample biobanking at the next level: combining tissue with living cell Repositories to promote precision medicine. Front Cell Dev Biol 2019;7:246.

93 Pickl M, Ries $\mathrm{CH}$. Comparison of 3D and 2D tumor models reveals enhanced HER2 activation in 3D associated with an increased response to trastuzumab. Oncogene 2009;28:461-8.

94 Pauli C, Hopkins BD, Prandi D, et al. Personalized In Vitro and In Vivo Cancer Models to Guide Precision Medicine. Cancer Discov 2017;7:462-77.

95 Vlachogiannis G, Hedayat S, Vatsiou A, et al. Patient-derived organoids model treatment response of metastatic gastrointestinal cancers. Science 2018;359:920-6.

96 Caoili EM, Davenport MS. Role of percutaneous needle biopsy for renal masses. Semin Intervent Radiol 2014;31:20-6.

97 Smith EH. Complications of percutaneous abdominal fine-needle biopsy. review. Radiology 1991:178:253-8.

98 Liu A, Pollard K. Biobanking for personalized medicine. In: KarimiBusheri $F$, ed. Biobanking in the 21st century. Cham: Springer International Publishing, 2015: 55-68.

99 Sherwood KR, Head MW, Walker R, et al. RNA integrity in post mortem human variant Creutzfeldt-Jakob disease (vCJD) and control brain tissue. Neuropathol Appl Neurobiol 2011;37:633-42.

100 Steu S, Baucamp M, von Dach G, et al. A procedure for tissue freezing and processing applicable to both intra-operative frozen section diagnosis and tissue banking in surgical pathology. Virchows Arch 2008;452:305-12.

101 Gaillard SL, Secord AA, Monk B. The role of immune checkpoint inhibition in the treatment of ovarian cancer. Gynecol Oncol Res Pract 2016;3:11.

102 Hamanishi J, Mandai M, Ikeda T, et al. Safety and antitumor activity of anti-PD-1 antibody, nivolumab, in patients with platinum-resistant ovarian cancer. J Clin Oncol 2015;33:4015-22.

103 Ott PA, Bang Y-J, Berton-Rigaud D, et al. Safety and antitumor activity of pembrolizumab in advanced programmed death ligand 1-positive endometrial cancer: results from the KEYNOTE-028 study. J Clin Oncol 2017;35:2535-41.
104 Le DT, Durham JN, Smith KN, et al. Mismatch repair deficiency predicts response of solid tumors to PD-1 blockade. Science 2017;357:409-13.

105 Borinstein SC, Beeler N, Block JJ, et al. A decade in banking Ewing sarcoma: a report from the children's Oncology Group. Front Oncol 2013;3:57.

106 Glover J, Krailo M, Tello T, et al. A summary of the osteosarcoma banking efforts: a report from the children's Oncology group and the QuadW Foundation. Pediatr Blood Cancer 2015;62:450-5.

107 Anderson C, ed. Manual for the Examination of Bone. CRC Press, 1982.

108 Kjaergaard J, Hatfield S, Jones G, et al. A Adenosine Receptor Gene Deletion or Synthetic $A_{2 A}$ Antagonist Liberate Tumor-Reactive $\mathrm{CD} 8{ }^{+} \mathrm{T}$ Cells from Tumor-Induced Immunosuppression. J Immunol 2018:201:782-91.

109 Hatfield S, Veszeleiova K, Steingold J, et al. Mechanistic justifications of systemic therapeutic oxygenation of tumors to weaken the hypoxia inducible factor 1alpha-mediated immunosuppression. Adv Exp Med Biol 2019;1136:113-21.

110 Sitkovsky MV. Lessons from the A2A adenosine receptor Antagonist-Enabled tumor regression and survival in patients with treatment-refractory renal cell cancer. Cancer Discov 2020;10:16-19.

111 Kepp O, Marabelle A, Zitvogel L, et al. Oncolysis without viruses - inducing systemic anticancer immune responses with local therapies. Nat Rev Clin Oncol 2020;17:49-64.

112 Pol JG, Caudana P, Paillet J, et al. Effects of interleukin-2 in immunostimulation and immunosuppression. J Exp Med 2020;217. doi:10.1084/jem.20191247. [Epub ahead of print: 06 Jan 2020].

113 Demaria S, Pikarsky E, Karin M, et al. Cancer and inflammation: promise for biologic therapy. J Immunother 2010;33:335-51.

114 Apetoh L, Smyth MJ, Drake CG, et al. Consensus nomenclature for $\mathrm{CD}^{+} \mathrm{T}$ cell phenotypes in cancer. Oncoimmunology 2015;4:e998538.

115 Dafni U, Michielin O, Lluesma SM, et al. Efficacy of adoptive therapy with tumor-infiltrating lymphocytes and recombinant interleukin-2 in advanced cutaneous melanoma: a systematic review and metaanalysis. Ann Oncol 2019;30:1902-13.

116 Han J, Lotze MT. The Adaptome as biomarker for assessing cancer immunity and immunotherapy. Methods Mol Biol 2020;2055:369-97.

117 Saada R, Weinberger M, Shahaf G, et al. Models for antigen receptor gene rearrangement: CDR3 length. Immunol Cell Biol 2007;85:323-32.

118 Jackson KJL, Kidd MJ, Wang Y, et al. The shape of the lymphocyte receptor repertoire: lessons from the B cell receptor. Front Immunol 2013;4:263.

119 Jackson KJL, Wang Y, Collins AM. Human immunoglobulin classes and subclasses show variability in VDJ gene mutation levels. Immunol Cell Biol 2014:92:729-33.

120 Collins AM, Jackson KJL. On being the right size: antibody repertoire formation in the mouse and human. Immunogenetics 2018;70:143-58.

121 Collins AM, Wang Y, Roskin KM, et al. The mouse antibody heavy chain repertoire is germline-focused and highly variable between inbred strains. Philos Trans $R$ Soc Lond B Biol Sci 2015;370:20140236.

122 Shitaoka $\mathrm{K}$, Hamana $\mathrm{H}$, Kishi $\mathrm{H}$, et al. Identification of tumoricidal TCRs from tumor-infiltrating lymphocytes by single-cell analysis. Cancer Immunol Res 2018;6:378-88.

123 Pasetto A, Gros A, Robbins PF, et al. Tumor- and NeoantigenReactive T-cell receptors can be identified based on their frequency in fresh tumor. Cancer Immunol Res 2016;4:734-43.

124 Formenti SC, Rudqvist N-P, Golden E, et al. Radiotherapy induces responses of lung cancer to CTLA-4 blockade. Nat Med 2018;24:1845-51

125 Zeh HJ, Bahary N, Boone BA, et al. A randomized phase II preoperative study of autophagy inhibition with high-dose hydroxychloroquine and Gemcitabine/Nab-Paclitaxel in pancreatic cancer patients. Clin Cancer Res 2020;26:3126-34. 